OPEN ACCESS

Edited by:

Harry J. Blokhuis,

Swedish University of Agricultural

Sciences, Sweden

Reviewed by:

Alison Hanlon,

University College Dublin, Ireland

Achim Spiller,

University of Göttingen, Germany

*Correspondence: Belinda Vigors belinda.vigors@sruc.ac.uk

Specialty section:

This article was submitted to Animal Welfare and Policy,

a section of the journal Frontiers in Animal Science

Received: 07 December 2020 Accepted: 02 March 2021 Published: 24 March 2021

Citation:

Vigors $B$, Ewing $D A$ and Lawrence $A B$ (2021) The Importance of Farm Animal Health and Natural Behaviors to Livestock Farmers: Findings From a Factorial Survey Using Vignettes.

Front. Anim. Sci. 2:638782. doi: 10.3389/fanim.2021.638782

\section{The Importance of Farm Animal Health and Natural Behaviors to Livestock Farmers: Findings From a Factorial Survey Using Vignettes}

\author{
Belinda Vigors $^{1 *}$, David A. Ewing ${ }^{2}$ and Alistair B. Lawrence ${ }^{1,3}$ \\ ${ }^{1}$ Scotland's Rural College (SRUC), Edinburgh, United Kingdom, ${ }^{2}$ Biomathematics and Statistics Scotland (BioSS), \\ Edinburgh, United Kingdom, ${ }^{3}$ Roslin Institute, University of Edinburgh, Edinburgh, United Kingdom
}

There is increasing interest in enabling positive experiences, not just minimizing negative experiences, to improve the welfare of farmed animals. This has influenced the growth of private agri-food standards and supported arguments to integrate animal welfare into policy on sustainability and climate change. However, much research finds that farmers predominantly focus on the minimization of negatives (i.e., health issues). This may impact the positioning of farmers within these wider societal debates, affecting their social license to farm. It is thus important to better understand farmers' priorities relating to the minimization of negative factors (e.g., health issues) and the promotion of positive experiences (i.e., natural behaviors). A novel $2 \times 2$ factorial survey using vignettes, which experimentally manipulated health (health issues minimized/not minimized) and natural behavior (natural behaviors promoted/not promoted) provision, was completed by livestock farmers ( $n=169$ ), mostly with extensive systems, in the UK and Republic of Ireland. The majority (88\%) considered "minimizing health issues" to be the most important factor for animal well-being. However, the overall welfare of animals was judged to be highest when both health and natural behaviors were supported. Several individual characteristics, including farming sector, production system, gender, belief in animal mind and business type influenced how participants judged the welfare of animals and the level of importance they gave to health and natural behaviors. Findings suggest that although farmers prioritize the minimization of health issues they want animals to be both healthy and able to express natural behaviors, and individual characteristics are important for understanding farmers' welfare-related judgements.

Keywords: farm animal welfare, farmer attitude, sustainability, food policy, factorial survey analysis

\section{INTRODUCTION}

There is growing awareness of and interest in the welfare benefits of promoting positive experiences in farm animals lives, both within science and society. From a welfare science perspective, this is seen in the continued development of positive animal welfare, which emerged as a response to criticisms of an over-emphasis on minimizing negative aspects of welfare in traditional welfare science (Lawrence et al., 2019). From a societal perspective, it is evident in both the increasing expectations of members of the public and growing market-based presence of private agri-food 
standards. Much research finds that members of the public associate animal welfare with animals being able to experience positive aspects of life (Miele, 2010; Miele et al., 2011) and largely prioritize "naturalness" over other aspects of welfare (Spooner et al., 2014a; Cornish et al., 2016; Thorslund et al., 2016). In response, private agri-food standards and welfare schemes have increasingly sought to include assessment criteria considered indicative of natural behavior expression (e.g., days spent at pasture, outdoor access) (Lundmark et al., 2018; Vogeler, 2019). This has contributed to an emerging gap between public standards-which provide a minimum standard of welfare-and private agri-food standards which seek to meet public expectations for higher welfare (Henson and Reardon, 2005; Lundmark et al., 2018). This adds to the complexity of farm animal welfare policy, with private standards becoming increasingly dominant governance instruments in the marketdriven context of farm animal welfare (Lundmark et al., 2018). There is also more recent evidence of both science and societal expectations for higher welfare informing debates of the importance of integrating animal welfare in wider policy issues, such as sustainability and food security (Buller et al., 2018), human health (European Commission, 2020), and climate change (Shields and Orme-Evans, 2015). Evidently, there is an awareness of a public desire for farm animals to experience positive lives (e.g., opportunities to express natural behaviors) and this is impacting both the development of and expectations for agri-food standards and related policy.

Yet, what of the farmers' position within these developments within science and society? Research finds that livestock farmers predominantly associate animal welfare with health and place particular emphasis on the minimization of pain, stress, disease, and other factors which may negatively impact the health of their animals (Bourlakis et al., 2007; Kauppinen et al., 2010; Faucitano et al., 2017). They also frequently link health and welfare to economic performance (Bourlakis et al., 2007; Skarstad et al., 2007; Kauppinen et al., 2010), using the productivity of their animals as an indicator of animal health and, in parallel, animal welfare (Bourlakis et al., 2007; Kauppinen et al., 2010; Vigors, 2019). Farmers' perspectives thus appear to be more closely aligned with the traditional welfare science views of minimizing harms as opposed to maximizing positive experiences. This may have implications for the position of farmers in respect to the growing interest in positive aspects of welfare seen in science (e.g., in positive animal welfare) and society (e.g., for "naturalness").

Although there is much evidence to suggest that farmers' attitudes to welfare are unidimensionally based around health (Hansson and Johan Lagerkvist, 2012), there is also evidence of heterogeneity in how farmers' construct and perceive animal welfare (Kirchner et al., 2014). Importantly, one of the main variances noted is in the importance farmers give to natural behaviors, where such variances have been linked to differences between farmers in welfare scheme (Kjaernes et al., 2008), production system (Spooner et al., 2014b), organic status (Skarstad et al., 2007), values (Hansson et al., 2018), and attitudes to animals (Hanna et al., 2009). As such, when variances between and within individual farmers are considered, welfare-related attitudes and decision-making may be more complex than is often suggested. This becomes important within a wider societal context where the views of farmers and the public are often presented as being discordant, with studies highlighting the health focus of farmers on the one side and the "naturalness" focus of the public on the other (Te Velde et al., 2002; Vanhonacker et al., 2008; Cornish et al., 2016). Such views have led to concerns that farmers may be at risk of failing to meet public demand and expectations relating to positive aspects of welfare (e.g., natural behaviors) (Hansson and Johan Lagerkvist, 2012). Yet, if there is heterogeneity between farmers in terms of their attitudes to welfare, it may only be particular groups or types of farmers who may be at risk in this respect.

At the same time, farmers have become the focus of public policy debates which, in seeking to address climate change, sustainability, and food security, may be at odds with public expectations for greater positive welfare and the values of some farmers (as above) relating to natural behaviors. Namely, "sustainable intensification," whereby farm animal production is encouraged to be more efficient (i.e., produce more with less resources), has been proposed as a means to reduce emissions from animal production, whilst supporting food security and sustainability (Garnett et al., 2013; Shields and Orme-Evans, 2015). However, research within welfare science has demonstrated that increasing the efficiency of animal production can come at the cost of animal's engaging in positive experiences (e.g., natural behaviors) (Rayner et al., 2020). Farmers are thus faced with operating within in an increasingly complex environment where protecting their 'social license' to farm could depend on how they address expectations for higher welfare along with climate change and sustainability issues (Williams and Martin, 2012). As Buller et al. (2018, p. 5) explain "The challenges facing agriculture over the next half-century are formidable; to be less environmentally damaging yet significantly increase food production while maintaining acceptable levels of animal welfare and human health."

Given the complex backdrop of increasing scientific and societal interest in supporting positive aspects of animals lives (e.g., natural behaviors) and the potential discordance between public expectations for welfare, the "sustainable intensification" of farming and farmers' welfare-related perspectives, it is important to better understand how farmers' prioritize key elements of welfare (i.e., minimizing health issues, promoting natural behaviors). Arguably, key policy decisions will have to be made in this context in the near future; having a better understanding of farmers' perspectives on key elements of welfare is therefore important for both designing policies on farm animal welfare (e.g., governance of welfare) and effectively situating welfare into wider policy debates (e.g., sustainability). As such, this study has two specific aims. First, it seeks to determine how important minimizing health issues and promoting natural behaviors are within farmers' welfare-related attitudes and judgements. Secondly, it aims to explore the extent to which individual differences (e.g., in sector, production system) influence farmers' attitudes to the importance of health and natural behaviors and their welfare-related judgements. 


\section{RELEVANT LITERATURE}

In the context of animal welfare, livestock farmers are primarily found to focus on and prioritize the minimization of health issues (Cornish et al., 2016). This is a consistent feature of farmers' perspectives on welfare, often regardless of sector, management system, or individual values and beliefs (Te Velde et al., 2002; Hansson and Johan Lagerkvist, 2012; Spooner et al., 2012; Hansson et al., 2018). However, beyond health, “a real diversity exists... among farmers when considering [animal welfare]" (Dockès and Kling-Eveillard, 2006, p. 248).

One of the main differences noted is in farmers attitudes to the importance of or role of natural behaviors in animal welfare. Here, much research links differences to variances in individual characteristics between farmers. For instance, Spooner et al. (2014b) found that producers who kept group-housed pigs emphasized natural behaviors more than producers who did not keep group-housed pigs; suggesting their welfare perspectives may have been influenced by the management and production system they operate or were familiar with. Farmers participating in organic or welfare-specific assurance schemes have also been found to place greater emphasis on natural behaviors than those in standard schemes (Bock and van Huik, 2007) and the type of business farmers operate (e.g., conventional, organic, large enterprises) may underlie their intrinsic (e.g., a personal desire) or extrinsic (e.g., to remain competitive) motivations to participate in welfare schemes (Bourlakis et al., 2007). Similarly, Skarstad et al. (2007) found that non-organic farmers referred to welfare in terms of good animal health while organic farmers associated welfare with natural behaviors. Interestingly, Dockès and Kling-Eveillard (2006) found a link between the type of production system a farmer had and their values; individuals with systems which support natural behaviors (e.g., group-housed calves, pigs on straw) described how they chose these systems because they were in line with their ethical values. The work of Hansson et al. (2018) further reveals how differences in personal values can lead to differences between farmers in terms of their attitudes to welfare. They found that "animal-centered" farmers placed more emphasis on non-use values (e.g., animal wellbeing) of animal welfare than farmers with "human-centered" or "business-oriented" values. Level of empathy and an individuals" attitude to animals are also known to impact farmers' assessments of and approach to managing welfare, with positive attitudes and higher levels of empathy associated with better welfare outcomes (Hanna et al., 2009; Kielland et al., 2010). Thus, when viewed together, attitudes to the importance of natural behaviors may vary between individual farmers, influenced by differences in management and production systems, sector, organic status, personal values, and attitude to animals.

More specific to positive welfare, farmers have been found to emphasize husbandry practices which may promote positive welfare and support natural behavior expression, such as; enabling animal autonomy, supporting play and social interactions, encouraging positive affect and developing positive human-animal relationships (Vigors and Lawrence, 2019). Notably, the priority farmers' gave to these different aspects varied according to their sector, management system, personal values, and the specific context of their farm and animals (Vigors and Lawrence, 2019). For instance, farmers who were found to value a more loosely-structured management system (i.e., use of limited human intervention) emphasized the importance of giving animals opportunity for autonomy over other welfare provisions. Conversely, this was less of a priority for farmers who valued a highly-structured management system (i.e., close control and monitoring of animals) (Vigors and Lawrence, 2019). Differences in the role farmers perceived they had in promoting natural behaviors, such as play, were also evident between different sectors. Those with more intensive systems, such as pig and poultry, described providing objects to support play or provide environment enrichment (Vigors and Lawrence, 2019). Conversely, farmers from sectors with extensive systems, such as beef and sheep, felt no direct promotion of play or other natural behaviors were required; this was perceived to be supported by the "natural," outdoor environment innate to their management system (Vigors and Lawrence, 2019). Thus, differences in values, sector and management system, again, may account for differences between farmers in terms of their attitudes toward and emphasis of natural behaviors.

In sum, although it is clearly evident that farmers strongly emphasize and prioritize the minimization of health issues within their management practices and welfare-related decisionmaking, there is also evidence that they consider the importance of natural behaviors to animal welfare. However, the importance farmers place on natural behaviors may be influenced by individual characteristics and differences (e.g., in values, management system, sector) resulting in greater heterogeneity in attitudes to natural behaviors than in attitudes to health. These warrant deeper investigation, particularly in the context of the, previously discussed, complex social and policy environment farmers operate in.

In response, this study seeks to examine how important farmers consider health and natural behaviors to be and under what conditions, whilst also exploring the extent to which personal characteristics may account for any differences in attitudes toward and judgements of animal welfare. Using a novel factorial survey design, we examine how varying levels of health and natural behavior provision influence farmers' judgements and assessments of different attributes of animal welfare. In addition, we directly examine how farmer characteristics (e.g., management system, assurance scheme membership, organic, sector etc.) may influence the importance they place on health and natural behaviors and how they judge the welfare of animals.

\section{MATERIALS AND METHODS}

\section{Survey Design}

Real-world judgement and decision-making often involves the consideration of multiple, complex, factors which have to be weighed against each other in order to reach a judgement (Taylor, 2006). This is certainly the case with animal welfare, where trade-offs frequently have to be made between different welfare provisions and decisions made based upon the specific nature of the situation or context (Appleby et al., 2014; Sandøe et al., 2019). Moreover, judgements are often influenced by the personal 
characteristics of the individual (Hox et al., 1991), as evident in the previous section.

Factorial surveys using vignettes provide a method to examine such complex judgements, where both the particulars of the situation in question and the individual's personal characteristics can impact judgement and decision-making (Hox et al., 1991). In a factorial survey, participants are asked to make judgements along specified dimensions based on information provided to them in a vignette (Hox et al., 1991). A vignette is a short description of a scenario created from the systematic selection and experimental manipulation of factors under study (Hox et al., 1991; Atzmüller and Steiner, 2010). By combining such experimental approaches with a traditional survey format (i.e., collect data on respondent-specific characteristics), factorial surveys offer a powerful means to determine which vignette factors may causally affect individual judgements and the underlying influence of personal characteristics on judgements (Hox et al., 1991; Taylor, 2006).

A factorial survey approach was taken in this study to examine how the two key factors in question - the importance of minimizing health issues and promoting natural behaviorsimpacted farmers' judgements and assessments of welfare and the extent to which personal characteristics influenced variances in judgements between participants. This approach resulted in the survey containing several key sections: (i) a factorial vignette scenario to capture participants' judgements of animal welfare under varying levels of health and natural behavior provision; (ii) measures of participant characteristics and demographic factors; (iii) attitudinal measures to capture overall attitude to the importance of health and natural behaviors. These sections are described in further detail below.

The survey (see Supplementary Material) was approved by Scotland's Rural College Social Science Ethics Committee and by the Scottish Government's Rural Affairs Food and the Environment Strategic Research programme.

\section{Judgement of Animal Welfare: $2 \times 2$ Factorial Vignette}

A factorial vignette, using a $2 \times 2$ experimental design, formed the main part of the survey. Participants were presented with one singular vignette; a hypothetical scenario describing the approach of a livestock farmer to minimizing health issues and promoting natural behaviors on their farm. Vignettes were created by manipulating the two factors of central interest in this study; health provision and natural behavior provision, and their two levels; health issues not minimized/health issues minimized and natural behaviors promoted/natural behaviors not promoted. This resulted in four possible vignettes, as described in Table 1. It is important to note that participants did not see the labels (e.g., farm 1: high health $\times$ low behavior) of each vignette, only the vignette narrative. In addition (see Supplementary Material), a descriptor of what is meant by "health" and "natural behaviors" was included below the vignette narrative.

Going forward, health issues minimized will be abbreviated to $\mathrm{HH}$ (High Health), health issues not minimized to LH (Low Health), natural behaviors promoted to $\mathrm{HB}$ (High Behavior), and natural behaviors not promoted to LB (Low Behavior). The
TABLE 1 | Vignette scenarios.

$\begin{array}{ll}\text { Farm 1: High Health } \times \text { Low } & \text { Farm 2: High Health } \times \text { High } \\ \text { Behavior } & \text { Behavior }\end{array}$

"I want my animals to be healthy. To me, this means having them stress free, pain free and injury free, whilst also being aware of any health issues that might be arising and dealing with them.

At the same time, I don't think I need to do anything specific to support natural behavioral expression in my animals"

\section{Farm 3: Low Health $x$ Low} Behavior

"When it comes to health, I am inclined to let nature take its course. l'd rather let the animal look after itself than intervene. For example, If I see the odd animal with a sore foot, l'll leave it alone and let it heal in its own time.

At the same time, I don't think I need to do anything specific to support natural behavioral expression in my animals"

"I want my animals to be healthy. To me, this means having them stress free, pain free and injury free, whilst also being aware of any health issues that might be arising and dealing with them.

At the same time, I want my animals to be able to express their natural behaviors. So, I try to make sure that they can go and have a wander around and see their surroundings, they can choose the animals they want to be around, lie down where they want to lie down and eat when they want to eat"

Farm 4: Low Health $\times$ High
Behavior
"When it comes to health, I am
inclined to let nature take its course.
l'd rather let the animal look after
itself than intervene. For example, If
I see the odd animal with a sore
foot, l'll leave it alone and let it heal
in its own time.
At the same time, I want my animals
to be able to express their natural
behaviors. So, I try to make sure
that they can go and have a wander
around and see their surroundings,
they can choose the animals they
want to be around, lie down where
they want to lie down and eat when
they want to eat"

wording and phrases used in the vignettes were taken from livestock farmers' descriptions of how they manage the health and promote the natural behaviors of their animals, collected during a prior qualitative interview study completed by the authors (see Vigors and Lawrence, 2019). This was done to ensure the vignettes reflected real-world conditions, used language relevant to livestock farmers and harnessed the validity of "folk" rather than scientific definitions of welfare (Weary and Robbins, 2019). In addition, the vignettes were framed in terms of the behavior or actions of a hypothetical farmer in proactively seeking to minimize (or not) health issues or directly promote (or not) natural behaviors rather than animals being e.g., healthy per se.

The four vignettes were randomized so that each respondent received only one vignette scenario. This is a recommended approach for factorial surveys to reduce the potential for response fatigue (caused by multiple vignette sets) and to ensure independence of observations between individuals, whilst also adding to the robustness of the experimental design (Taylor, 2006). Based on the information provided in the vignette, participants were then asked to rate (i.e., judge) (on a slider scale from 0 to 10 , where 0 indicated poor, 5 average, and 10 excellent) 
several dimensions relevant to animal welfare: (i) the overall wellbeing of the animals in the scenario; (ii) the physical health of the animals; (iii) the mental health of the animals and; (iv) the productivity of the animals. The latter was considered important for inclusion in light of the previously discussed literature which suggests farmers link welfare and health with the productivity of their animals (e.g., Bourlakis et al., 2007; Skarstad et al., 2007; Kauppinen et al., 2010). The purpose of this section was to examine the impact of varying, and at times conflicting, levels in provisions for health and natural behaviors on respondents' assessments of different welfare attributes-animal well-being, physical and mental health, and productivity. This enables an examination of how the rating of welfare attributes may causally vary according to variances in the level of health and natural behavior provision (i.e., high health/low health, high behavior, low behavior).

The vignette section of the survey also included a question aimed at capturing how respondents thought other farmers would rate the overall well-being of the animals described in the vignette. This was included to examine the potential effect of social norms, whereby participants may respond in a manner they think is in line with the expectations of others (i.e., peers). The design of this question followed the recommendations of Bicchieri (2016), who describes that one way to assess social norms is to ask people how they believe others may respond to a similar question.

Two open-ended qualitative questions were also included in the vignette section. Here, participants were asked to (i) explain why they gave the overall well-being rating that they did, and (ii) describe what, if anything, they would change about the farm described in the vignette. This was done to provide richer detail on participants' reasoning and perceptions of the vignette scenario.

\section{Participant Characteristics}

The survey collected relevant socio-demographic and farmer characteristics. This is a key element of factorial surveys, which combine experimental design (i.e., $2 \times 2$ factorial vignettes) with traditional survey design, enabling investigation at the vignette and individual level and how both impact judgements and attitudes (Hox et al., 1991; Taylor, 2006). Socio-demographic measures included multiple-choice questions for gender, age, highest level of education, annual household income, dietary preferences (i.e., regularly eat meat, flexitarian, vegetarian, vegan, pescatarian, other), type of area living (i.e., urban, rural), and geographic location (i.e., UK, Republic of Ireland). The belief in animal mind (BAM) scale (from Knight et al., 2004) was also included to capture respondents' attitudes to animal sentience. The scale included four questions, with participants rating the extent to which they agreed (on a slider scale from 0 to 10 , with 0 indicating complete disagreement and 10 complete agreement) that farm animals: (i) are unaware of what is happening to them (i.e., not conscious); (ii) capable of experiencing feeling and emotion; (iii) able to think to some extent to solve problems and make decisions; and are (iv) like computer programs, responding to urges without awareness of what they are doing (Hills, 1995; Knight et al., 2004).
Questions relevant to individual characteristics thought to impact farmers' perspectives of welfare were also included. Specifically, multiple-choice questions for organic status (organic, non-organic), membership in farm assurance scheme (whether member of a scheme or not), farming sector (sheep, beef, dairy, pig, broiler chicken, laying-hen, poultry other, other) management system (e.g., whether animals were housed yearround or part of the year, etc.), type of farm business (family-run, commercial partnership, direct-to-buyer, small-holding, other), tenure (number of years farming), and the number of animals they manage. A self-reported measure of input intensitythe extent to which inputs such as concentrated feeds and fertilizers are increased to produce one unit of output (European Commission, 2017) - was also included to gain a general insight into the intensiveness/extensiveness of each respondent's farm.

\section{Overall Attitude to Importance of Minimizing Health Issues and Promoting Natural Behaviors}

A further section (separate from the vignette section and presented at a later stage in the survey) captured respondents' overall attitude to the importance of minimizing health issues and promoting natural behaviors within farm animal welfare. Participants were asked to rate (on a scale from 0 to 10 , where 0 indicated not important at all, 5 of average importance, and 10 extremely important), how important they considered (i) the minimization of health issues and (ii) the promotion of natural behaviors to be for the overall well-being of farm animals. To further determine which factor participants considered was the most important, a binary choice question asked respondents to select between "minimizing health issues" and "promoting natural behaviors" as the most important factor for animal well-being.

\section{Data Collection}

The survey was open to livestock farmers, from all sectors, and of all farm sizes, in the UK and Republic of Ireland. The survey was disseminated online using social media and in online newsletters with the assistance of several farming sector organizations, agricultural colleges and the farming press. As such, a nonprobability sampling approach was used. No incentives for completing the survey were offered, with participants completing the survey on a voluntary basis.

\section{Data Preparation}

The survey received 248 responses. Responses that were mostly incomplete (e.g., more than half of survey not completed) were removed, resulting in a final sample of 169 individuals (which contained a small number of incomplete responses for some participant characteristic categories) and a $68 \%$ item nonresponse rate. Quantitative responses were entered into SPSS, Version 25 (IBM Corp, 2017), for analysis. Data was checked for multicollinearity and normality. There were no multicollinearity issues (as assessed by a VIF $<10$ ) within the explanatory variables (i.e., participant characteristics and level of health and behavior provision in vignette scenario). Normality was also assessed by a visual inspection of Q-Q Plots and the distributions were determined as normal. 
Several categories of the participant characteristic variables were removed or recategorised for quantitative analysis due to some being unselected or having small sample sizes. Gender was regrouped to "male" and "female" as the "in another way" and "prefer not to say" categories had no responses. Education was regrouped into "non-degree" (combining "primary" and "secondary"), "undergraduate," "post-graduate," and "other." For dietary preferences, "vegan" was removed (due to no responses), vegetarian and pescatarian was regrouped into a "does not eat meat" category, "regularly eat meat" responses were recategorised as "eats meat" and the flexitarian category remained unchanged. The type of area living variable was recategorised as either urban (combining "urban" and "suburban") or rural (combining "semirural" and "rural"). The "broiler chicken" category was removed from the farming sector variable, as it was unselected. Responses relating to "sector" and "type of farm enterprise" were multiple response; participants could select more than one category (e.g., beef and sheep). Each category within both these variables were transformed into dummy variables (e.g., member of beef sector or not member of beef sector) and treated as singular predictor variables. The four item BAM scale was examined for reliability and found to have a Cronbach's alpha of 0.60. This is in line with previous applications of this scale (i.e., Knight et al., 2004 reported a Cronbach's alpha of 0.62). A summated scale of BAM was thus created to provide a mean score for each participant's overall BAM (i.e., higher means indicated a greater belief in farm animal mind).

\section{Data Analysis}

\section{Analysis of Factorial Vignettes}

There were high levels of correlation (Cronbach's alpha $>0.7$ ) between the vignette scenario outcome variables (i.e., ratings of well-being, physical and mental health, productivity, and social norms). As such, a multivariate linear regression was used to examine the impact of the different levels of health (i.e., $\mathrm{HH} / \mathrm{LH}$ ) and natural behavior (i.e., HB/LB) provision, and participant characteristics on the vignette judgement variables (i.e., wellbeing, physical health, mental health, social norms). To assess the overall model, only terms statistically significant at the 5\% level were included in the model and its overall performance was measured by the adjusted $\eta^{2}$ of value of the model (adjusted $\eta^{2}$ gives the proportion of variance explained adjusted by the number of terms in the model). Following this, all statistically significant and non-significant terms were included and the model refitted to examine the full range of the effects of the explanatory variables (i.e., health and natural behavior provision, participant characteristics) on the outcome variables (i.e., wellbeing, physical health, mental health, productivity, social norms). Wilks' $\lambda$ (which considers each term having been adjusted for inclusion of the others) was used to assess the impact of the explanatory variables on the combined outcome variables. Assessments of partial $\eta^{2}$ were used to determine the individual effects of each explanatory variable on each single outcome variable. To examine the impact of social norms, a paired $t$-test was used to assess the difference between how participants rated overall well-being and the rating they gave for how they thought other farmers would rate well-being.

\section{Analysis of Qualitative Responses to Vignette Scenarios}

Qualitative responses to the vignette scenario questions; (i) Why did you give this rating for overall well-being? and; (ii) If you were to change anything about this farm; what would that be? were entered into MaxQDA (Version 2018.2) for analysis. Responses to (i) were first analyzed using a sentiment analysis approach, which involved categorizing responses according to whether they were positive, negative, or neutral in terms of how the participants felt about the vignette scenario they were assigned to. Responses within each vignette and within each sentiment category were then further analyzed thematically. This involved working through each response and coding their content according to the specific points, or themes, discussed by respondents. This resulted in several overarching themes within each sentiment category (i.e., positive, negative, neutral), and sub-themes capturing reasons why participants rated well-being as they did. Responses to (ii) were analyzed using a content analysis approach. This involved looking for commonality in descriptive words conveying what participants would change and counting, using MaxQDA software, how often they were mentioned across participants.

\section{Analysis of Overall Attitude to Importance of Minimizing Health Issues and Promoting Natural Behaviors}

A paired samples $t$-test was used to determine differences in participants' ratings (on a scale of 0-10) of the importance of "minimizing health issues" and "promoting natural behaviors."

A cumulative odds ordinal logistic regression with proportional odds was run to determine the effect of participant characteristics (i.e., gender, age, education, income, tenure, dietary preferences, type of area living, geographic location, assurance scheme membership, farming sector, management system, business type, number of animals managed, organic status, BAM, input intensity) on the importance given to minimizing health issues and promoting natural behaviors. The vignette health and behavior provision variables were also included as predictors in the model to determine whether the information participants were previously exposed to in the vignette scenario had any effect on how they rated the importance of health and natural behaviors.

The following section presents the results of the aforementioned analyses. Throughout, when not otherwise stated, "significant" means significant at the 5\% level.

\section{RESULTS}

\section{Sample Descriptives}

The majority of the sample (62\%) were from the United Kingdom (UK). There was an almost even split between genders $(53 \%$ male, $47 \%$ female) for the total sample (however, more females were from the UK). The mean age of the total sample was 41 (range: 18-75). The majority of the sample were educated to degree level, holding either undergraduate (44\%) or postgraduate (22\%) certifications. Participants with "other" levels of education (17\%) included those with vocational training qualifications 
(e.g., NVQ's) and other third-level education such as higher diplomas. An annual household income of $£ 20,000-£ 34,999$ was the most common response (29\%) amongst UK participants, while for Irish respondents a household income of $£ 35,000$ $£ 49,999$ was the most common (20\%). Dietary preferences were somewhat homogeneous with a large majority (92\%) indicating they regularly eat meat. Almost all participants (96\%) lived in rural areas. The majority (31\%) had been farming for more than 30 years, closely followed by those who had been farming between 11 and 20 years $(27 \%)$.

The majority of participants were from the beef (54\%) and/or sheep (52\%) sector, with most Irish participants (63\%) from the beef sector and most UK participants (70\%) from the sheep sector. The dairy sector was the third most prevalent (27\%), followed by a smaller number in the pig (9\%), laying-hen (9\%), and "other poultry" sectors (e.g., duck, turkey) (3\%). A small number (8\%) also selected "other" for sector which included responses such as keeping goats. Most participants had a familyrun business $(71 \%)$ and were a member of a farm assurance scheme (67\%). There were very few participants who farmed organically (3\%) and these were only in the UK. Beyond the majority of the sample who were non-organic (86\%), $4 \%$ selected "other" describing various different approaches such as, "free range dairy," "farming with an organic ethos," and "limited use of chemicals." With regards to how they managed their animals, the majority of the sample (50\%) indicated their animals were housed for part-of the year and outdoors for part-of the year, followed by those who indicated their animals were outdoor all-year round (21\%). Only a small number (7\%) housed animals all year-round, most of which were in the UK $(n=10)$ and 1 in the ROI. Several participants (11\%) also selected "other" for management system, describing approaches such as animals being outdoors all year but with free access to a barn, only housing animals in extreme weather conditions, or species-specific management (e.g., "cattle housed in winter, sheep outdoors all the time" or "sheep housed only for lambing"). The remainder housed their animals but gave them access to the outdoors some of the time (2\%), or all of the time $(2 \%)$. The mean rating for BAM was $7.66(S D=1.5)$ and the mean rating for input intensity was $4.88(S D=2.19)$. Complete demographic and demographic information split by country (i.e., UK and ROI) can be found in Table 2 .

\section{Factorial Vignette Findings}

The random assignment of participants in the different vignettes resulted in $24 \%$ being assigned to farm one $(\mathrm{HH} \times \mathrm{LB}), 21 \%$ to farm two $(\mathrm{HH} \times \mathrm{HB}), 28 \%$ to farm three $(\mathrm{LH} \times \mathrm{LB})$, and $27 \%$ to farm four $(\mathrm{LH} \times \mathrm{HB})$. To determine how participants judged the welfare of the animals within each scenario, the mean ratings for each welfare judgement attribute (i.e., ratings for overall wellbeing, physical health, mental health, and productivity) within each vignette were examined. Farm two $(\mathrm{HH} \times \mathrm{HB})$ received the highest mean ratings for each welfare attribute, followed by farm one $(\mathrm{HH} \times \mathrm{LB})$ and farm four $(\mathrm{LH} \times \mathrm{HB})$. Farm three $(\mathrm{LH} \times$ LB) received the lowest mean ratings for all welfare judgement variables. Figure 1 displays the difference in mean judgement ratings for each welfare attribute across the different levels of health (i.e., high health/low health) and behavior provision (i.e., high behavior/low behavior).

Pairwise comparisons of mean differences indicated that the differences in judgements of welfare attributes between the different vignette scenarios were statistically significant. Table 3 presents these significant mean differences and ranks each vignette scenario according to the highest and lowest mean rating for each judgement variable (i.e., well-being, physical health, mental health, productivity, social norms). Of particular note are the mean differences between scenarios where there is some trade-off in the provision of health and natural behaviors i.e., farm $1(\mathrm{HH} \times \mathrm{LB})$ and farm $4(\mathrm{LH} \times \mathrm{HB})$. As indicated by Figure 1 and Table 3, a scenario where health provision is high but behavior provision is low (i.e., farm 1) results in higher mean ratings for each judgement variable than scenarios where health provision is low but behavior provision is high (i.e., farm 4). In other words, low health provision results in low mean ratings of welfare attributes even if behavior provision is high. A slight exception to this is for ratings of mental health, where the mean difference between farm 1 and farm 4 is slight $(M=0.31, p<$ 0.01; see Table 3), although still in favor of high health provision resulting in higher mean ratings than high behavior, as evident in Figure 1 above.

To capture social norms, participants were also asked to rate how they thought other livestock farmers would rate the overall well-being of the animals described in the vignette they were assigned to. Paired samples $t$-tests revealed that respondents assigned to farm one $(\mathrm{HH} \times \mathrm{LB})$, farm three $(\mathrm{LH} \times \mathrm{LB})$, and farm four $(\mathrm{LH} \times \mathrm{HB})$ vignettes believed that other livestock farmers would give higher ratings for well-being than them, with significant respective mean differences of .73 (95\% CI, $0.21-$ $1.24, p=0.007), 0.88$ (95\% CI, 0.35-1.40, $p=0.002$ ), and 0.67 (95\% CI, $0.12-1.22, p=0.017$ ). There was no evidence that participants who received the farm two $(\mathrm{HH} \times \mathrm{HB})$ vignette believed that other livestock farmers would rate the overall wellbeing of the animals in the scenario any differently than they did, with an estimated mean difference of -0.37 (95\% CI, $-0.87-0.12$, $p=0.135)$.

\section{The Impact of Vignette Factors and Participant Characteristics on Judgements of Vignette Scenarios}

A multivariate regression was fitted to examine the impact of the different levels of the vignette conditions and participant characteristics on judgement variables (i.e., well-being, physical health, mental health, social norms). In the model including only statistically significant explanatory variables the combined predictor variables (i.e., health provision, behavior provision, participant characteristics) had the greatest effect on judgements of overall well-being, $F_{(57,154)}=4.58 ; p<0.001$; adjusted $\eta^{2}$ $=0.60$ (where adjusted $\eta^{2}$ gives the proportion of variance explained adjusted by the number of terms in the model). This was followed by physical health, $F_{(57,154)}=3.72 ; p<$ 0.001 ; adjusted $\eta^{2}=0.52$, productivity, $F_{(57,154)}=3.42 ; p<$ 0.001 ; adjusted $\eta^{2}=0.51$, social norms, $F_{(57,154)}=3.18 ; p<$ 0.001 ; adjusted $\eta^{2}=0.50$ and mental health judgements, $F_{(57,154)}$ $=2.56 ; p<0.001$; adjusted $\eta^{2}=0.40$. 
TABLE 2 | Demographic data of study participants.

\begin{tabular}{|c|c|c|c|c|c|c|}
\hline & \multicolumn{2}{|c|}{ UK $(n=105)$} & \multicolumn{2}{|c|}{ Ireland $(n=64)$} & \multicolumn{2}{|c|}{ Total $(n=169)$} \\
\hline \multicolumn{7}{|l|}{ Gender } \\
\hline Male & 40 & 38 & 49 & 77 & 89 & 53 \\
\hline Female & 65 & 62 & 15 & 23 & 80 & 47 \\
\hline \multicolumn{7}{|l|}{ Age } \\
\hline 30-39 & 15 & 14 & 18 & 28 & 33 & 20 \\
\hline $40-49$ & 21 & 20 & 8 & 13 & 29 & 17 \\
\hline $50-59$ & 17 & 16 & 11 & 17 & 28 & 17 \\
\hline 60 and over & 27 & 26 & 8 & 13 & 35 & 21 \\
\hline Prefer not to say & 12 & 11 & 6 & 9 & 18 & 11 \\
\hline \multicolumn{7}{|l|}{ Education } \\
\hline Other & 20 & 19 & 8 & 13 & 28 & 17 \\
\hline \multicolumn{7}{|l|}{ Household income } \\
\hline$<20,000$ & 13 & 12 & 5 & 8 & 18 & 11 \\
\hline $20,000-34,999$ & 30 & 29 & 11 & 17 & 41 & 24 \\
\hline 35,000 to 49,999 & 24 & 23 & 13 & 20 & 37 & 22 \\
\hline 50,000-74,999 & 11 & 11 & 13 & 20 & 24 & 14 \\
\hline 75,000-99,999 & 7 & 7 & 7 & 11 & 14 & 8 \\
\hline Over 100,000 & 5 & 5 & 5 & 8 & 10 & 6 \\
\hline Prefer not to say & 15 & 14 & 10 & 16 & 25 & 15 \\
\hline \multicolumn{7}{|l|}{ Dietary preferences } \\
\hline 5 years and under & 10 & 10 & 5 & 9 & 15 & 10 \\
\hline $6-10$ & 12 & 12 & 10 & 18 & 22 & 14 \\
\hline $11-20$ & 26 & 26 & 16 & 28 & 42 & 27 \\
\hline $21-30$ & 19 & 19 & 9 & 16 & 28 & 18 \\
\hline More than 30 & 32 & 32 & 16 & 28 & 48 & 31 \\
\hline Prefer not to say & 1 & 1 & 1 & 2 & 2 & 1 \\
\hline $\begin{array}{l}\text { (Missing due to incomplete } \\
\text { data) }\end{array}$ & & & & & 12 & 7 \\
\hline \multicolumn{7}{|l|}{ Sector } \\
\hline Sheep & 70 & 70 & 12 & 21 & 82 & 52 \\
\hline Beef & 48 & 48 & 36 & 63 & 84 & 54 \\
\hline Dairy & 11 & 11 & 31 & 54 & 42 & 27 \\
\hline Pig & 12 & 12 & 2 & 4 & 14 & 9 \\
\hline Laying-hen & 12 & 12 & 2 & 4 & 14 & 9 \\
\hline Poultry other & 4 & 4 & 0 & 0 & 4 & 3 \\
\hline Other & 12 & 12 & 1 & 2 & 13 & 8 \\
\hline \multicolumn{7}{|c|}{ Number of animals managed } \\
\hline Unspecified & 1 & 1 & 1 & 2 & 2 & 1 \\
\hline$<99$ & 21 & 21 & 13 & 23 & 34 & 22 \\
\hline
\end{tabular}


TABLE 2 | Continued

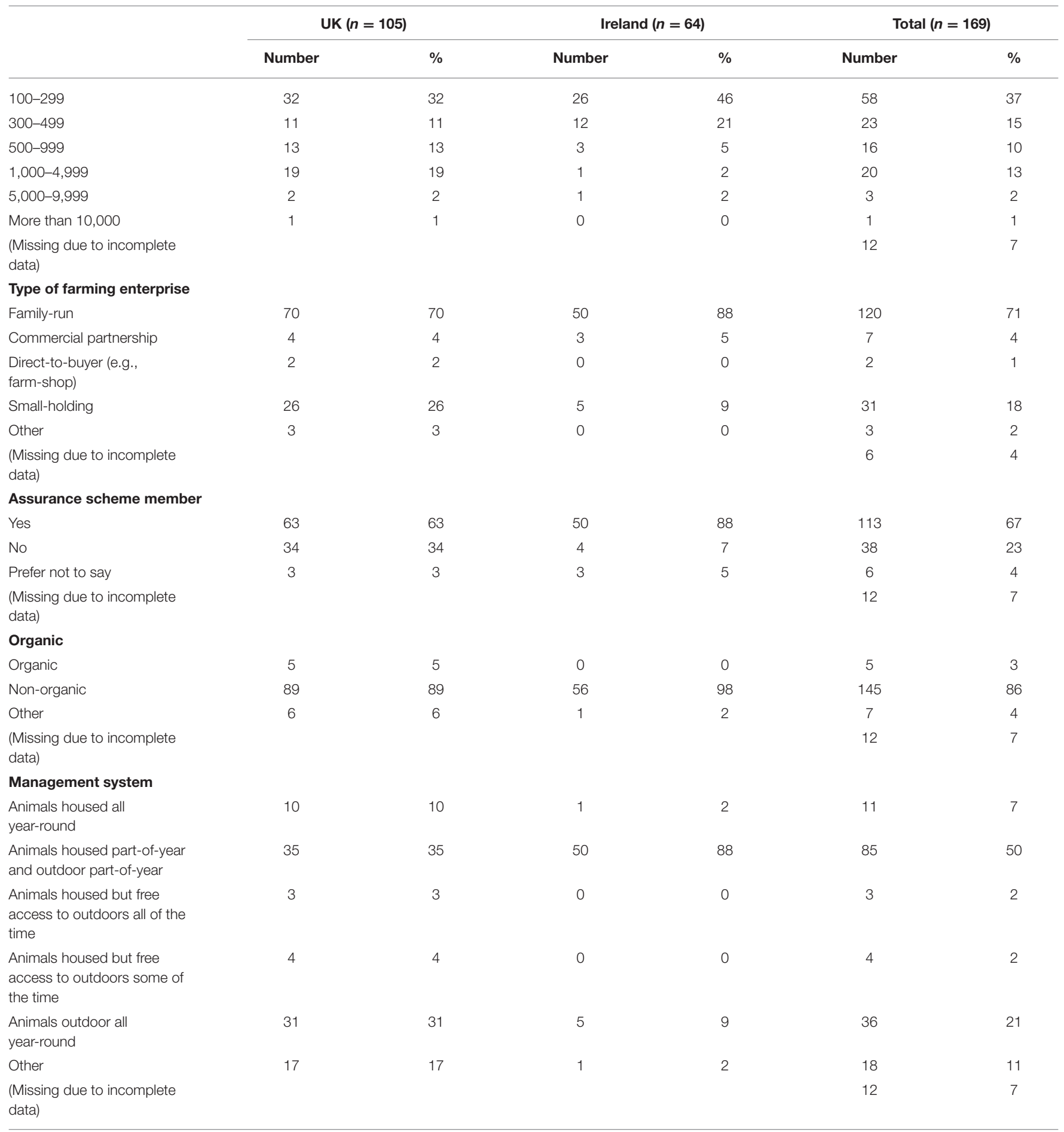

Percentages rounded to whole number.

In the model including all the explanatory variables, including participant characteristics and health and behavior provision, information on whether health issues were minimized or not (i.e., health provision variable) significantly explained more of the variability in the combined judgement variables (i.e., well-being, physical health, mental health, productivity, social norms) than any other predictor variable, Wilks' $\Lambda=0.394 ; F_{(5,93)}=28.62$; $p<0.001$. The vignette information participants received on whether natural behaviors were promoted or not (i.e., behavior provision variable) also had a significant impact on the combined 


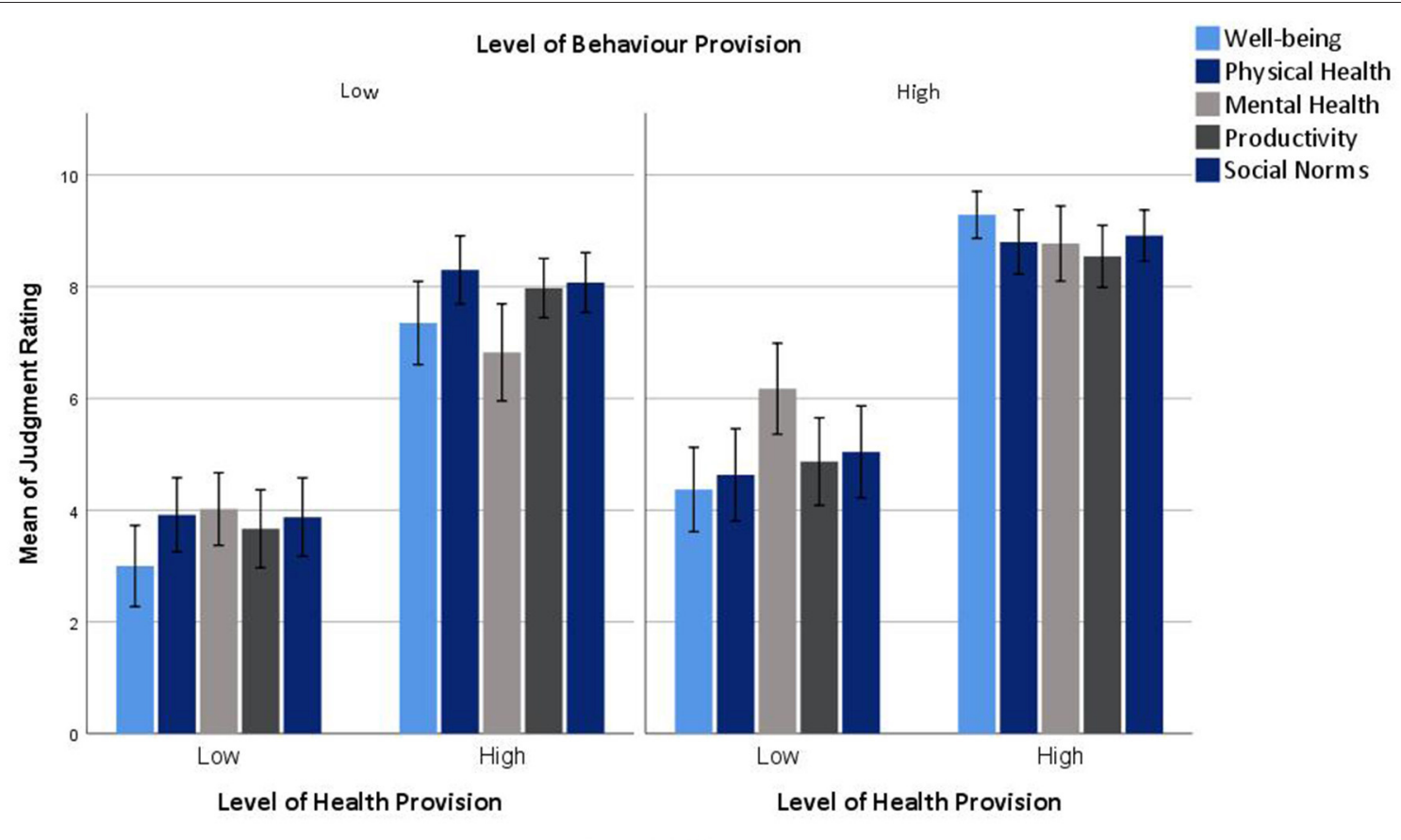

Error Bars: $95 \% \mathrm{Cl}$

FIGURE 1 | Mean rating of well-being, physical health, mental health, productivity, and social norms by levels of health and natural behavior provision.

judgement variables, although it explained less of the variance than health provision; Wilks' $\Lambda=0.71 ; F_{(5,93)}=7.54 ; p<0.001$. None of the participant characteristic variables included in the multivariate model significantly explained the variance of the combined outcome variables.

In terms of the impact of each predictor variable on each judgement variable (i.e., well-being, physical health, mental health, productivity, social norms), following adjustment for other variables, health provision, again, explained more of the variance of each judgement variable than any other predictor variable. Its greatest impact was on judgements of overall wellbeing; $F_{(1,97)}=117.54 ; p<0.001 ; \eta^{2}=0.55$, followed by productivity; $F_{(1,97)}=99.80 ; p<0.001 ; \eta^{2}=0.51$, physical health; $F_{(1,97)}=99.40 ; p<0.001 ; \eta^{2}=0.51$, social norms; $F_{(1,97)}$ $=92.09 ; p<0.001 ; \eta^{2}=0.49$ and finally, mental health; $F_{(1,97)}$ $=34.25 ; p<0.001 ; \eta^{2}=0.26$. Behavior provision also had a significant (but lower than health provision) effect on each of the judgement variables. Its strongest effect was on judgements of mental health; $F_{(1,97)}=27.66 ; p<0.001 ; \eta^{2}=0.22$, followed by well-being; $F_{(1,97)}=27.01 ; p<0.001 ; \eta^{2}=0.22$, social norms; $F_{(1,97)}=14.06 ; p<0.001 ; \eta^{2}=0.13$ and productivity; $F_{(1,97)}=$ $11.13 ; p=0.001 ; \eta^{2}=0.10$. Its lowest effect was on ratings of physical health; $F_{(1,97)}=8.45 ; p=0.005 ; \eta^{2}=0.08$.

Several participant characteristic variables also had a significant effect on some of the judgement variables. As depicted in Table 4, operating either a family-run business or commercial partnership was a positive predictor of judgements of well-being, physical, and mental health. Having a family-run business was also a positive predictor of judgements of animal productivity. This indicates that participants with these business types judged the welfare of animals in each scenario to be more positive than those of other business types (i.e., direct-tobuyer, small-holding). Being a member of the beef sector also had a significant effect on judgements of well-being, physical health, and productivity. Specifically, beef sector was a positive predictor, indicating members of the beef sector judged these welfare attributes to be more positive than those from other farming sectors (i.e., sheep, dairy, pig, laying-hen, poultry-other, other). Dairy sector also had a significant, but negative, effect on judgements of mental health indicating that members of the dairy sector judged mental health to be lower than participants from other sectors. BAM also had a significant and positive effect on judgements of productivity and social norms, indicating that participants with a greater BAM rated the ability of an animal to be productive (in the different vignette scenarios) higher than those with a lower BAM. Similarly, participants with a greater BAM gave higher ratings for social norms than those with a lower BAM. The remaining participant characteristics, including geographic region (i.e., UK or ROI) were not found to have a significant effect on the judgement variables.

\section{Qualitative Responses: What Influenced Participants Ratings of Overall Well-Being?}

In order to gain a deeper insight into what may have influenced participants' judgements and how they decided on a rating for animal well-being, an open-ended question asked respondents to discuss why they gave the rating for overall well-being that they did. As previously described, these findings were analyzed both 
TABLE 3 | Pairwise comparison of mean differences between vignette scenarios for judgements of welfare attributes.

\begin{tabular}{|c|c|c|c|c|c|}
\hline & \multicolumn{4}{|c|}{ Reference category } & Ranking \\
\hline Farm $1(\mathrm{HH} \times \mathrm{LB})$ & 0 & $-2.65^{\star}$ & $4.27^{\star}$ & $2.48^{\star}$ & 2nd \\
\hline Farm $2(\mathrm{HH} \times \mathrm{HB})$ & $2.65^{\star}$ & 0 & $6.92^{*}$ & $5.13^{\star}$ & 1 st \\
\hline Farm $3(\mathrm{LH} \times \mathrm{LB})$ & $-4.27^{\star}$ & $-6.92^{\star}$ & 0 & $-1.79^{\star}$ & 4th \\
\hline \multicolumn{6}{|l|}{ Physical health } \\
\hline Farm $1(\mathrm{HH} \times \mathrm{LB})$ & 0 & $-1.03^{\star}$ & $4.58^{\star}$ & $3.10^{*}$ & 2nd \\
\hline Farm $2(\mathrm{HH} \times \mathrm{HB})$ & $1.03^{\star}$ & 0 & $5.61^{*}$ & $4.13^{\star}$ & $1 s t$ \\
\hline Farm $3(\mathrm{LH} \times \mathrm{LB})$ & $-4.58^{\star}$ & $-5.61^{*}$ & 0 & $-1.48^{*}$ & 4th \\
\hline Farm $4(\mathrm{LH} \times \mathrm{HB})$ & $-3.10^{\star}$ & $4.13^{*}$ & $1.48^{*}$ & 0 & 3rd \\
\hline \multicolumn{6}{|l|}{ Mental health } \\
\hline Farm $4(\mathrm{LH} \times \mathrm{HB})$ & $-0.31^{*}$ & $-2.61^{\star}$ & $2.56^{\star}$ & 0 & $3 r d$ \\
\hline \multicolumn{6}{|l|}{ Productivity } \\
\hline Farm $1(\mathrm{HH} \times \mathrm{LB})$ & 0 & $-1.21^{*}$ & $4.5^{\star}$ & $2.88^{\star}$ & 2nd \\
\hline Farm $2(\mathrm{HH} \times \mathrm{HB})$ & $1.21^{*}$ & 0 & $5.71^{*}$ & $4.08^{\star}$ & $1 s t$ \\
\hline Farm $3(\mathrm{LH} \times \mathrm{LB})$ & $-4.5^{\star}$ & $5.71^{*}$ & 0 & $-1.62^{\star}$ & 4th \\
\hline Farm $4(\mathrm{LH} \times \mathrm{HB})$ & $-2.88^{\star}$ & $-4.08^{\star}$ & $1.62^{*}$ & 0 & $3 r d$ \\
\hline \multicolumn{6}{|l|}{ Social norms } \\
\hline Farm $1(\mathrm{HH} \times \mathrm{LB})$ & 0 & $-1.60^{\star}$ & $4.33^{\star}$ & $2.63^{\star}$ & 2nd \\
\hline Farm $2(\mathrm{HH} \times \mathrm{HB})$ & $1.60^{*}$ & 0 & $5.93^{\star}$ & $4.23^{\star}$ & $1 s t$ \\
\hline Farm $3(\mathrm{LH} \times \mathrm{LB})$ & $-4.33^{\star}$ & $-5.93^{\star}$ & 0 & $-1.70^{\star}$ & 4th \\
\hline
\end{tabular}

*Shows the mean difference is significant at the 0.05 level.

Adjustment for multiple comparisons: Least Significant Difference.

semantically and thematically. Figure 2 illustrates the outcome of the semantic analysis, detailing the percentage of positive, negative, and neutral responses within each vignette scenario and the themes that emerged within each sentiment category.

\section{Farm One: Health Issues Minimized $\times$ Natural Behaviors Not Promoted}

Sentiment analysis indicated a mostly positive response to farm one, with responses including $60 \%$ positive sentiments, $37 \%$ negative, and 3\% neutral. Health being supported was the predominant reason given within positive responses. Here, participants mainly focused on the animals in the scenario being free from pain and stress which, therefore, indicated to them that the animals' main needs would be met "If the animal is stress, pain and ilness free then overall the vast majority of its needs is being met" (Beef \& Sheep, ROI). Several participants also discussed this scenario in terms of the farmer responsible for the animals, perceiving them as an individual who cares for the welfare of their animals; "The farmer clearly has a concern for the welfare of their livestock" (Sheep, UK). In sum, positive responses here came from the fact that health issues were minimized, which participants perceived indicated that both the animals' needs were being met and that the farmer appropriately cared for their animals and their welfare.

The negative sentiments (37\%) directed toward this scenario predominantly focused on the lack of support for natural behaviors; "Some indication of appreciation of natural behaviours would have increased my score" [Pig \& Poultry (free-range turkey), UK]. Interestingly, the reasons why natural behaviors were considered important varied between individuals. For some, supporting natural behaviors was considered to support health; "There are health benefits to ensuring an animal can express natural behaviours" (Sheep, UK), for others, there were productivity benefits; "Efforts must be made to allow natural behaviour as it can enhance farm KPIs" (Pig, ROI). Participants also linked natural behaviors with the mental health of the animal, as described in the following narrative (notable for the level of detail it provides); "Psychological well-being can have a detrimental or beneficial effect on an animal's physical health. An animal that is consistently deprived of contact with others of its kind, or conversely placed in an overcrowded situation, can stop eating, engage in repetitive adverse behaviour (e.g., tail biting in pigs), adopt pica-like dietary habits, be subjected to bullying and fall foul of perceived idiopathic health issues (infertility, agalactia, wasting syndromes etc.). It is remiss in this age of information to 
TABLE 4 | Impact of significant participant characteristics on judgement variables.

\begin{tabular}{|c|c|c|c|c|c|c|c|c|}
\hline & \multirow[t]{2}{*}{$B$} & \multicolumn{2}{|c|}{$95 \% \mathrm{Cl}$ for $\mathrm{B}$} & \multirow[t]{2}{*}{ SE $B$} & \multirow[t]{2}{*}{$\boldsymbol{F}$} & \multirow[t]{2}{*}{$d f$} & \multirow[t]{2}{*}{$p$} & \multirow[t]{2}{*}{ Partial $\eta^{2}$} \\
\hline & & LL & UL & & & & & \\
\hline \multicolumn{9}{|l|}{ WELL-BEING } \\
\hline \multicolumn{9}{|l|}{ Business type } \\
\hline Family-run & 3.00 & 0.63 & 5.37 & 1.20 & 6.31 & 1 & 0.014 & 0.061 \\
\hline Commercial partnership & 3.95 & 1.09 & 6.82 & 1.44 & 7.52 & 1 & 0.007 & 0.072 \\
\hline \multicolumn{9}{|l|}{ Farming sector } \\
\hline Beef & 1.36 & 0.24 & 2.48 & 0.56 & 5.82 & 1 & 0.018 & 0.057 \\
\hline \multicolumn{9}{|l|}{ PHYSICAL HEALTH } \\
\hline \multicolumn{9}{|l|}{ Business type } \\
\hline Family-run & 2.91 & 0.51 & 5.30 & 1.21 & 5.82 & 1 & 0.018 & 0.057 \\
\hline Commercial partnership & 3.23 & 0.35 & 6.12 & 1.45 & 4.94 & 1 & 0.029 & 0.048 \\
\hline \multicolumn{9}{|l|}{ Farming sector } \\
\hline Beef & 1.25 & 0.12 & 2.38 & 0.57 & 4.83 & 1 & 0.03 & 0.047 \\
\hline \multicolumn{9}{|l|}{ MENTAL HEALTH } \\
\hline \multicolumn{9}{|l|}{ Business type } \\
\hline Family-run & 2.59 & 0.03 & 5.15 & 1.29 & 4.04 & 1 & 0.047 & 0.04 \\
\hline Commercial partnership & 4.46 & 1.37 & 7.55 & 1.56 & 8.22 & 1 & 0.005 & 0.078 \\
\hline \multicolumn{9}{|l|}{ Farming sector } \\
\hline Dairy & -1.51 & -2.98 & -0.05 & 0.74 & 4.19 & 1 & 0.043 & 0.041 \\
\hline \multicolumn{9}{|l|}{ PRODUCTIVITY } \\
\hline Belief in animal mind & 0.34 & 0.04 & 0.64 & 0.15 & 4.94 & 1 & 0.029 & 0.048 \\
\hline \multicolumn{9}{|l|}{ Business type } \\
\hline Family-run & 2.47 & 0.11 & 4.82 & 1.19 & 4.33 & 1 & 0.04 & 0.043 \\
\hline \multicolumn{9}{|l|}{ Farming sector } \\
\hline Beef & 1.39 & 0.28 & 2.49 & 0.56 & 6.14 & 1 & 0.015 & 0.06 \\
\hline \multicolumn{9}{|l|}{ SOCIAL NORMS } \\
\hline Belief in animal mind & 0.32 & 0.01 & 0.63 & 0.16 & 4.27 & 1 & 0.042 & 0.042 \\
\hline
\end{tabular}

B, Unstandardised regression coefficient; Cl, Confidence Interval; LL, Lower Level; UL, Upper Level.

believe that so long as an animal doesn't have a visible or observed affliction that it is entirely healthy, if its psychological needs haven't been met as diligently as its physical ones" (Sheep, Beef \& Layinghen, UK). In addition, some participants proposed ways to support natural behaviors, highlighting the role of environment enrichments; "Stimulus such as brushes allow animals to groom, improving wellbeing" (Dairy, ROI), and the support of social interaction; "Social grouping is key to some species-more than 'entertainment"' (Sheep, UK). In addition, a small number of respondents expressed negative sentiments toward the farmer in the scenario, describing them as being reactive rather than proactive and for not doing more to promote animal well-being; "Would not go out of his way to make the animals happy" (Beef \& Dairy, ROI).

A small number (3\%) of responses demonstrated neutral sentiments. These were predominantly individuals who, rather than discussing the scenario, discussed their own personal farm, describing their own management practices and what they do to support the health and natural behaviors of their own animals. These included factors such as reducing stress, handling animals calmly, ensuring animals have enough space and comfortable housing, keeping animals in familial groups and numerous health provisions to ensure high health. A small number of responses also expressed a belief that most farmers are doing their best and cannot get it right all of the time; "Nobody's perfect" (Sheep, UK), indicating they may have been more forgiving in their ratings of well-being than other participants.

\section{Farm Two: Health Issues Minimized $x$ Natural Behaviors Promoted}

Sentiment analysis indicated a large $(80 \%)$ positive response to this scenario. Discussion here primarily focused on the farmer, describing them as a "good farmer" who prioritized the well-being of their animals: "These sound like the views of a good farmer, wanting the best for his or her animals" (Sheep \& Laying-hen, UK); "Animal wellbeing is front and centre of this farmers mind-set" (Dairy, ROI). The farmer, in the scenario, was perceived to be a "good farmer" because they considered the animal's perspective, understood their needs and/or prioritized the animals in their management decisions: "Good set up with animals at heart of it" (Sheep, $\mathrm{UK})$; "The farmer obviously understands the needs of the animals he/she is caring for" (Sheep, UK). Several respondents also positively commented on how both health issues were 


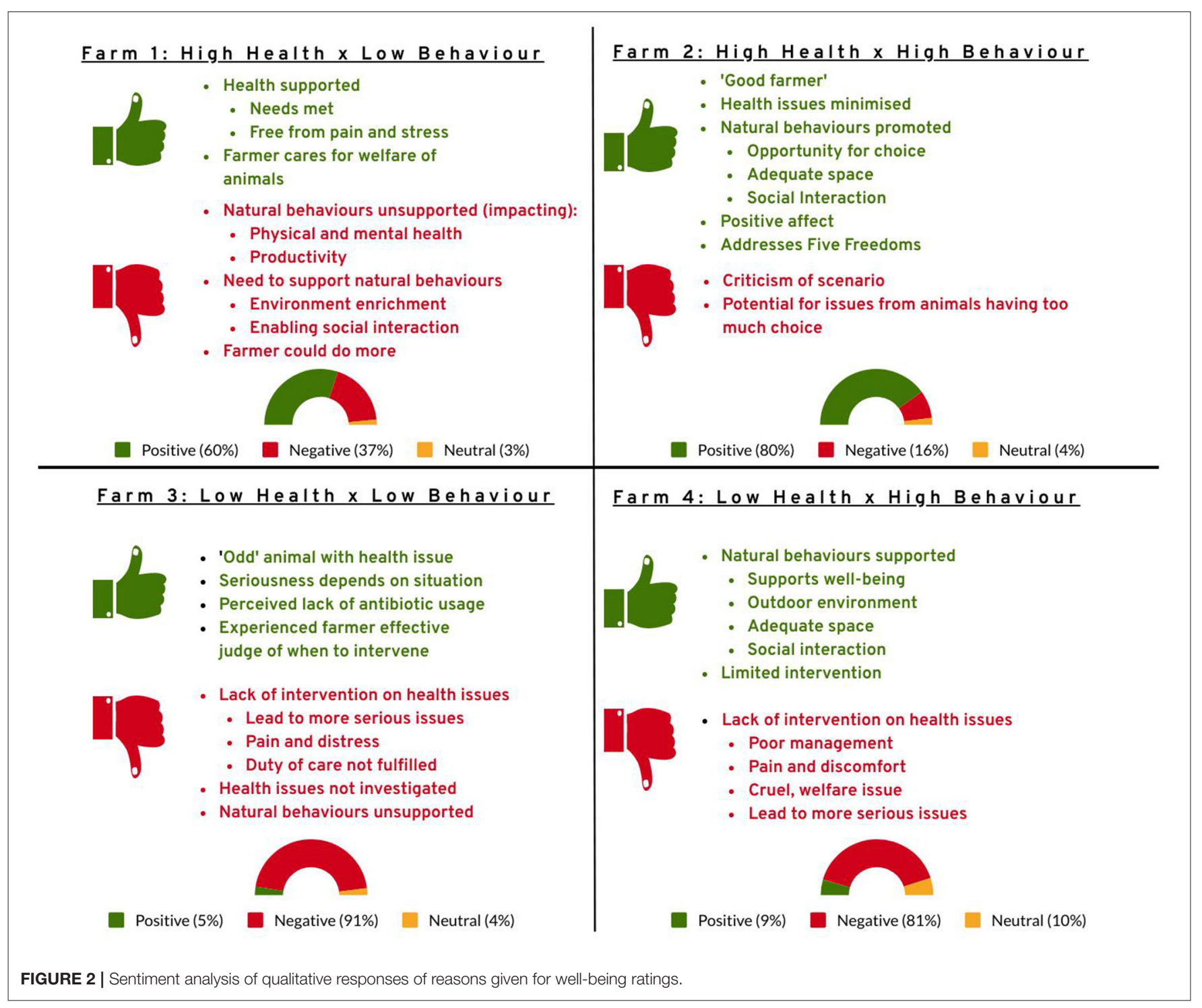

minimized and natural behaviors promoted, highlighting how this would minimize negative factors (e.g., stress) and support positive behaviors (e.g., social interaction): "Animals are living in a stress free environment and able to choose their preferred behaviours and social contacts" (Dairy \& Sheep, ROI). Several participants expanded on and described how they perceived the scenario was positively supporting natural behaviors, mentioning factors such as animal's having freedom and the opportunity to exert choice; "The freedom to display natural behaviours and make decisions for themselves" (Beef, ROI), adequate space provision; "He gives them space to roam" (Beef \& Sheep, UK), and the importance of social interaction; "Cattle have strong family and friendships and bonds-they like to see one another and groom/play" (Beef, Sheep \& Dairy, UK). However, some responses mentioned only health issues being minimized when discussing what positively influenced their rating of well-being: "Emphasis on animal health and low stress"
(Sheep, UK). A small number of responses also associated this scenario with positive affect, describing it in terms of animals being happy; "Happy Cows" (Dairy, UK) and contented; "Animals should be....kept in conditions that allow them to be contented" (Sheep \& Laying-hen, UK). Interestingly, a very small number of participants directly drew on the five freedoms, judging the scenario positively because of a perception that it addressed all five of the freedoms; "Addresses five freedoms including ability to express natural behaviour" (Seep \& Dairy, UK).

There were a small number of negative sentiments (16\%) expressed about this vignette. These were criticisms of the scenario, describing how the factors presented in it do not necessarily lead to better welfare; "Just because they can wander around and choose where they want to lie doesn't guarantee better well-being" (Pig, UK). In addition, one respondent cautioned that providing animals with too much choice (e.g., food choice) may 
have negative effects; "It seems an excellent scenario but it isn't necessarily sensible to allow animals to eat too much" (Sheep, UK).

Neutral sentiments (4\%) were, again, respondents who discussed their own personal farms rather than the specifics of the scenario. In this case, they mentioned factors such as having an extensive management system (e.g., sheep free to graze on hill land), farming in a traditional way (e.g., non-intensively, with traditional breeds), limiting animal stress (e.g., not using dogs to herd), and a focus on preventative healthcare (e.g., preventing lameness).

\section{Farm Three: Health Issues Not Minimized $x$ Natural Behaviors Not Promoted}

Responses to the scenario were overwhelmingly negative (91\%) in their sentiment. For the majority, this was due to the lack of intervention in relation to dealing with health issues (i.e., the sore foot). These, many participants argued, should in the very least be investigated, stressing that a lack of intervention could lead to more serious problems arising; "Many diseases will selfcure but leaving issues such as lameness untreated will eventually lead to larger outbreaks and a greater overall welfare problem" (Beef \& Sheep, UK), and would result in animals being in pain, discomfort or distress; "You need to intervene to avoid animals being in discomfort" (Sheep, ROI); "Animals in pain should be treated to prevent suffering" (Beef, ROI). Within this, several participants argued that intervention to deal with health issues is particularly important when animals are kept in a non-natural environment; "I don't like to see my animals suffer unnecessarily, especially if they are living in an unnatural environment, for example on slatted floors" (Pig, UK), and that humans therefore have a duty to care for their health; "Animals kept on a farm are removed from nature and must have their health proactively managed by the herd-owner" (Dairy, ROI).

Many respondents were also critical of the lack of support for natural behaviors in this scenario. Here, participants expressed views that animals should be able to express their natural behaviors; "Animals should be allowed to exhibit/ experience natural behaviour as much as possible within a normal production system" (Beef \& Sheep, UK), and described different ways in which natural behaviors could be promoted and supported; "Allowing an animal to express normal behaviour is sometimes about doing nothing. Sometimes it's about doing something, or providing something, i.e., a cow brush, or providing a situation i.e., allowing a hen to scratch for food or a pig to dig" (Beef \& Sheep, UK). Closely related to this, was a view that the extent to which natural behaviors need to be promoted can depend upon the type of system or environment an animal was in: "For the behaviour it depends what the housing is like-the animals may be in a very extensive system, which doesn't need many specific things to aid natural behavioural expression" (Pig, UK). One individual also highlighted how a lack of support for natural behaviors may further exacerbate a health issue, describing how; "If there was no effort to support natural behaviour expression, a sick animal may not have the space and quiet that it might choose to seek out" (Sheep, UK). Interestingly, one of the criticisms directed toward this scenario was described within terms familiar to the positive welfare literature, where the participant specifically argued that the primary issue with this scenario was a lack of interest in, or support for, positive aspects of welfare: "'Freedom from pain/suffering' are key parts of the basic requirements for 'A Life Worth Living'. By letting nature take its course this farmer is not abiding by that. Well-being means moving toward 'A Good Life' in all aspects of livestock care. In an unnatural farmed situation we need to ensure animals have the maximum opportunity to express natural behaviour. This farmer is not doing that" (Sheep \& Other (Goat), UK).

The small number of positive responses (5\%) to this scenario were primarily based on the fact that only an "odd" animal was described as having a sore foot in the vignette, and was therefore not a whole group problem; "Only a small proportion of group" (Sheep, UK). What was particularly notable was how participants considered and weighed up the context they perceived the animals were in, influencing their judgements of the scenario; "It depends on how long the animal has been lame for. If it has been lame for ten days very maximum, I would get it in to see whether it has an abscess/infection. The reason I gave 5, is that farmer stated the odd animal rather than a number of animals" (Sheep, UK). A small number of participants also reasoned that a lack of intervention, if the animal was not suffering too much, may be positive if this reduced antibiotic usage; "I think some farmers are too quick to intervene with antibiotics when we are trying to reduce the usage, so it is good in that respect. But if the animal is in pain, or antibiotics would aid the recovery, then the farmer shouldn't hesitate in jabbing the pig" (Pig, UK). In addition, some participants felt that an experienced farmer would be able to effectively judge when there is a need to intervene on a health issue; "An experienced farmer will know when to intervene and when to leave to heal itself" (Beef \& Sheep, UK). Overall, it was evident that positive responses were based on the consideration of specific conditions or contexts which may ameliorate the potential negative impact a lack of intervention may have on animal health.

Neutral responses (4\%) were, again, participants who discussed their own personal farm rather than the scenario.

\section{Farm Four: Health Issues Not Minimized $\times$ Natural Behaviors Promoted}

Responses to this scenario were largely negative $(81 \%)$. The primary reason for these negative responses was the lack of intervention in dealing with health issues (e.g., the 'sore foot); there was an almost unanimous view that "The sore foot needs to be looked after" (Beef, ROI). For many, a lack of intervention was considered poor management and a cause for concern due to the pain and discomfort that may result; "If an animal is identified with an obvious health problem it should be treated accordingly to ensure maximum comfort is given to the animal to improve its wellbeing" (Beef, UK). Some even described the situation as cruel, causing suffering or a welfare issue; "Allowing [animals] to heal naturally with no vet treatment plan is negligent and causes suffering" (Sheep, UK). Several participants demonstrated strong, personal views on the lack of health intervention, reflecting on how they would approach and deal with the scenario; "If there is an animal lame, I wouldn't leave it untreated, I would have to check and see what the problem was, it could be something as 
simple as a stone in the hoof and by removing it you're taking away that chance of it developing into a more painful situation for the animal" (Beef \& Dairy, ROI). In addition, respondents also expressed concerns that a lack of intervention could lead to the condition worsening or more serious health problems; "You need to intervene with animal health and welfare i.e., sore feet. Leaving it alone can cause more health issues" (Sheep. UK). Such negative views of the lack of health intervention further contributed to the view that, at the very least, the health issue should be investigated before any decisions made (e.g., to leave to heal naturally or intervene); "The farmer could have at least examined the foot of the animal rather than observe from a distance. It could have just needed debris removed or a natural treatment could have been administered" (Sheep \& Poultry Other, UK). A small number of participants also expressed the view that, because farm animals are domesticated and rely on human intervention, they are responsible for their well-being and therefore are duty-bound to address health issues; "Livestock are domestic animals and early intervention is often necessary" (Sector unknown, ROI); "I believe when animals are in your care, you should treat any discomfort they have no matter how small" (Sheep, UK). Interestingly, one participant constructed their criticism of a lack of intervention on health issues through its effect on productivity; "I think it unlikely that a commercial farmer would leave an animal with a 'sore foot' to 'heal itself' as such animals are less likely to be able to feed well and grow well enough to be profitable" (Sheep, UK). Thus, overall, respondents viewed this scenario negatively because health issues were not minimized, expressing concerns for the negative impact this would have on animal well-being, its potential to cause suffering or lead to greater health issues and considering it a sign of poor management or neglect.

Despite the large portion of negative responses, participants also demonstrated positive responses ( $9 \%$ ), predominantly due to the support for natural behaviors which participants commended and considered a positive contributor to animal well-being; "Allowing animals to express normal behaviour should always be encouraged and this contributes to well-being in a positive way" (Sheep, UK). Within this, respondents largely focused on opportunities for animals to be outside; "I like animals to have access to outside when suitable" (Beef, UK), describing this as a natural environment for animals; "Good appreciation of animals need for habitat and natural behaviour" (Beef \& Sheep, $\mathrm{UK}$ ), and emphasized the benefits of animals having space and opportunities for social interaction "Plenty of space and exercise is beneficial for the animals' mental and physical health, they are able to get away from animals that pick on them and are able to socialise freely" (Beef, UK). In addition, a very small number of respondents positively focused on "letting nature take its course" in regards to dealing with health issues. Specifically, they felt that some intervention would be necessary but agreed with the general attitude; "Sore foot unlikely to heal on its own, however letting nature take its course is almost always best" (Beef \& Sheep, UK).

Despite these positive sentiments toward this scenario, due to natural behaviors being supported, perceptions of it were largely negative. Within their discussions, participants gave an indication as to why it was viewed so negatively, despite natural behaviors being supported. Namely, they described and viewed health as the priority; "The second part of the sentence I'd agree with, it suggests good well-being, but health is a primary importance and it seems the farmer ignores small indicators of illhealth" (Sheep \& Poultry Other, UK); "Animal health should be a priority" (Beef, UK). Such responses suggest that participants give precedence to health such that, in a situation where there is a trade-off between health and natural behaviors, animal wellbeing cannot be considered positive if only natural behaviors are supported.

There were also neutral responses to this scenario (10\%). Again, these were responses where participants discussed their own personal farm, describing factors such as how out-wintering their animals results in lower levels of disease and health-issues or how they treat health issues on their own farm. In addition, several also discussed how the impact of a health issue on animal well-being may depend on the context or situation the animal is in. For instance, the number of animals the farmer may have to manage; "Farmer sounds inclined to neglect however the size of the operation and type of animal may make the individual care of one foot impractical" [Laying-hen (free range), UK], or how intervening may cause stress for a greater number of animals; "Understandably catching a whole flock to treat one lame sheep can cause stress, but that one lame sheep can then spread the issue to other animals in the flock without intervention" (Beef \& Sheep, UK). Thus, a weighing up of different contextual factors which may influence their decision was evident in participants' discussions and judgements of this scenario.

\section{Qualitative Responses: What Would Participants Change About the Scenario?}

To gain an insight into what participants considered may be lacking or needed improving within each scenario, they were asked to describe what they would change about the scenario they were assigned to. Findings are presented in Figure 3, which illustrates the content analysis of responses in a wordcloud, whereby the most common responses are represented by the largest word. Responses reflect and support the views expressed in the previous section. Specifically, that there is a need for more support of natural behaviors in farm one $(\mathrm{HH} \times \mathrm{LB})$, that farm two $(\mathrm{HH} \times \mathrm{HB})$ was largely an excellent scenario where "nothing" needed to be changed and that both farm three $(\mathrm{LH} \times$ $\mathrm{LB})$ and farm four $(\mathrm{LH} \times \mathrm{HB})$ required a consideration of health and intervention to minimize health issues.

\section{Overall Attitude to the Importance of Minimizing Health Issues and Promoting Natural Behaviors}

To assess participants' overall attitude to the importance of minimizing health issues and promoting natural behaviors for animal well-being, they were asked to select which of these factors they thought was most important and, in addition, rate (on a scale from 0 to 10) the importance of each. The majority of participants $(87.6 \%)$ considered "minimizing health issues" to be the most important factor for animal well-being. When asked to rate how important each factor was, "minimizing health issues" 


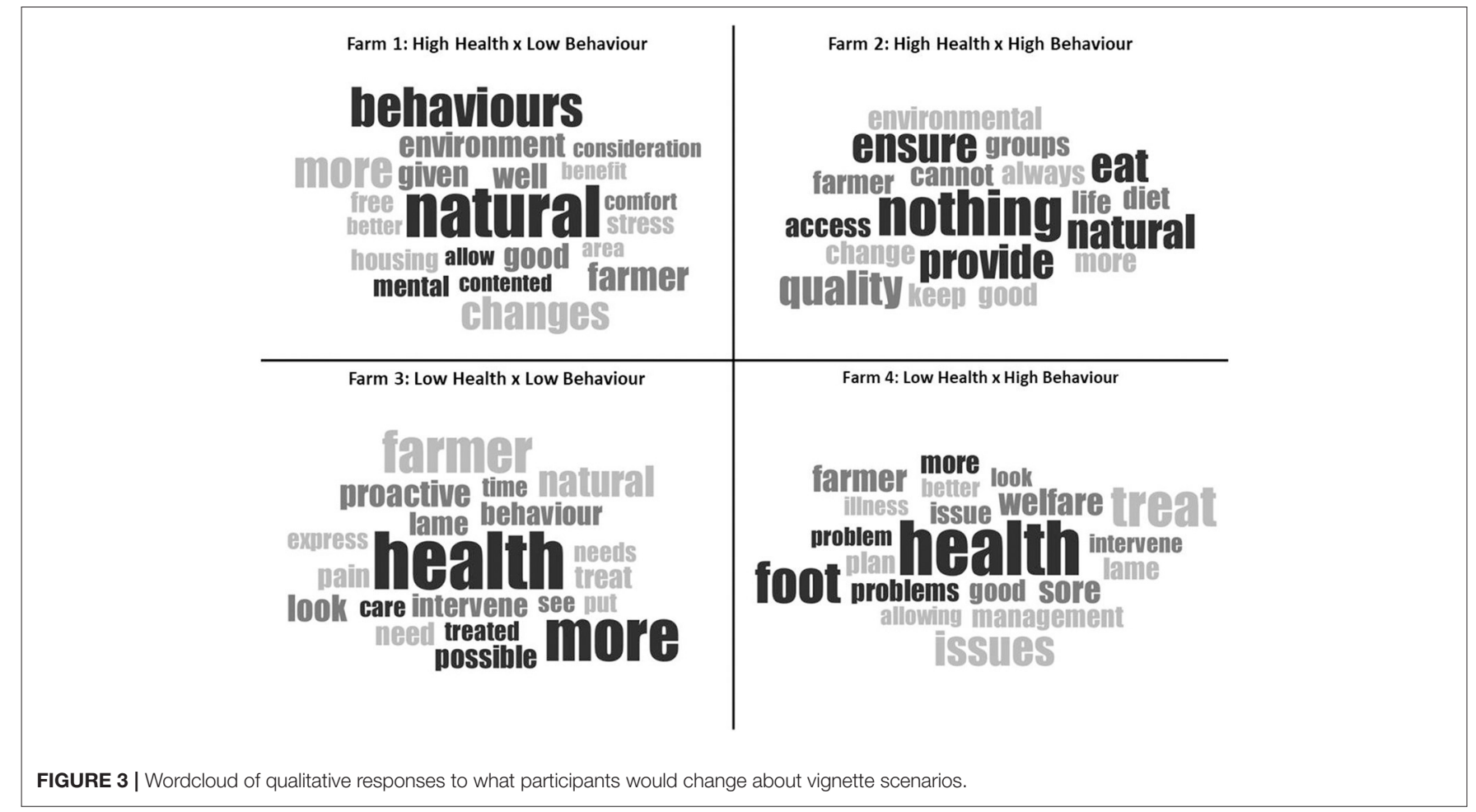

was rated slightly higher $(M=9.69, S D=0.60)$ than "promoting natural behaviors" $(M=8.57, S D=1.53)$. A paired sample $t$-test indicated that the difference in ratings was statistically significantly different, with minimizing health issues considered more important for overall well-being, than promoting natural behaviors by 1.124 (95\% CI, 0.899-1.349); $t_{(169)}=9.870, p<$ 0.001 ; Cohen's $d=0.76$.

\section{Factors Impacting Ratings of the Importance of Health and Natural Behaviors}

For the importance of minimizing health issues, none of the predictor variables had a significant effect on participants' ratings of this variable.

For the importance of promoting natural behaviors, gender (Wald $\mathrm{x}_{(1)}^{2}=4.18, p=0.041$ ) and the way in which participants managed their animals (i.e., management system) (Wald $x_{(5)}^{2}$ $=11.22, p=0.047$ ) were found to be significant predictors. However, these were not adjusted for multiple testing (due to constraints within the functionality of SPSS) and given their closeness to the $p<0.05$ significance threshold, it is likely they would not remain significant if adjusted for other predictors. Nevertheless, the direction of their effect is interesting. Males were significantly less likely to give a higher rating for the importance of promoting natural behaviors than females, with an odds ratio of 0.38 (95\% CI, 0.15-0.96). In other words, males were more likely to give a lower rating for the importance of natural behaviors than females. Participants who kept the majority of their animals outdoors all year round were 3.97 times $(95 \% \mathrm{CI}$, 1.24-12.75) more likely to give higher ratings for the importance of promoting natural behaviors than participants who housed animals for part-of the year and kept them outdoors part-of the year; a significant effect, Wald $x_{(1)}^{2}=5.38, p=0.020$. The information participants received on health and behavior provision in the vignette scenarios were not significant predictors of attitudes to the importance of natural behaviors.

\section{DISCUSSION}

This study set out to examine the importance farmers give to minimizing health issues and promoting natural behaviors within their welfare-related attitudes and judgements, and the extent to which individual differences may influence this. The findings of this study are broadly in line with and support previous research which finds that farmers prioritize the minimization of health issues within their conceptions of animal welfare (e.g., Bourlakis et al., 2007; Kauppinen et al., 2010). When asked to make a choice between minimizing health issues and promoting natural behaviors, the majority of participating farmers selected minimizing health issues as the most important factor for animal well-being. Furthermore, when asked to rate how important they considered each to be for animal well-being, participants' attitudinal responses indicated that minimizing health issues was considered slightly more important for animal well-being than promoting natural behaviors. Importantly, beyond these attitudinal factors, this study also found that the information provided on health provision (i.e., whether health issues were minimized or not) in the vignette scenarios had more of an impact on participants' judgements than any other variable, including participant characteristics. Thus, how an animal's health is being managed appears to be a 
central consideration within farmers' welfare related decisionmaking. Previous research has demonstrated a connection between farmers' attitudes and their welfare-related behavior and judgements, with the former often considered to predict the latter (Hansson and Johan Lagerkvist, 2012). As such, the impact of health provision on participants' judgements of the vignette scenarios could be explained by a pre-existing attitude that health is the most important factor for animal well-being. Within the context of a changing policy landscape, this is a particularly important finding for understanding how farmers' perspectives may contribute to them having different welfare priorities from other key stakeholders (e.g., public). However, as the vignettes provided information only on health and natural behaviors, it would be erroneous to suggest that health provision is the primary consideration for farmers in every welfare-related situation. Rather, as Kristensen and Jakobsen (2011) suggest, farmers' judgement and decision-making is likely to be contextbound where, in the context of the presented vignettes, health was judged to be the factor of primary importance.

It is notable that welfare was judged most positively when both health issues were minimized and natural behaviors promoted, as revealed by the farm two $(\mathrm{HH} \times \mathrm{HB})$ scenario receiving the most positive (i.e., most highly rated) judgements. This suggests that, while health may play a central role in their judgements of welfare, what farmers want is for animals to be both healthy and able to express their natural behaviors. Notably, participants' qualitative responses to scenarios where natural behaviors were not promoted (i.e., farm one and farm three), criticized the lack of support for natural behaviors. They also suggested ways in which natural behaviors could be supported (e.g., providing enrichment, social interaction), further revealing how they view and construct what is relevant for natural behaviors. Moreover, when asked what they would change about such scenarios, greater promotion of natural behaviors was the most common response to those assigned to low behavior (i.e., natural behaviors not promoted) vignettes. As such, findings suggest that farmers also care about natural behaviors, or at least recognize a lack of support for them as an issue, and are knowledgeable of mechanisms and means to enable them. Natural behavior provision also had a significant impact on participants' judgements of the different welfare attributes in the vignette scenarios (albeit less than health provision but more than any personal characteristics). Interestingly, compared to its impact on other judgement variables, natural behavior provision most strongly impacted judgements of animal mental health. This suggests that different welfare-relevant provisions (e.g., health, natural behaviors) may be perceived by farmers to have different roles or be important for different aspects of an animal's welfare. That farmers appear to consider natural behaviors particularly relevant to animal mental health is in line with much of the positive welfare literature, which argues that for animals to experience positive affect they require opportunities to engage in positive experiences (e.g., Boissy et al., 2007; Mellor, 2012). As such, the findings of this study suggest that both health and natural behaviors matter to farmers. Such a finding adds to the debate on the potential animal welfare consequences of increasing the efficiency of animal production to address sustainability and climate change (e.g., Shields and Orme-Evans, 2015; Clay et al., 2020); it may also be at odds with farmers' personal welfare expectations and values relating to natural behavior expression.

In considering our findings together, it is possible to suggest that farmers view and judge the importance of these two factors of welfare on a continuum. Participants' judgements, when there was a trade-off between the provision of health and natural behaviors, provide further support for this. Welfare-related judgements were always rated lower when health issues were not minimized, even if natural behaviors were simultaneously supported in the vignette scenarios. It is thus possible to theorize that farmers, when simultaneously presented with information on health and natural behaviors, may first look to health provision as a criteria for good welfare. In situations where health is not taken care of but natural behaviors are, the former may be perceived to offset any good done by the latter. Indeed, several participants emphasized in their qualitative responses that natural behaviors are important but that dealing with health issues should be a priority. Such views somewhat echo perspectives which place animal experience on a continuum from "pains" to "pleasures" (Fraser and Duncan, 1998), with farmers situating their primary role as that of minimizing "pains" so that the animal is free and able to engage in "pleasures" of their own accord (Vigors and Lawrence, 2019). Indeed, the views and judgements of participating farmers are not that different to those found by Duncan (1996, cited in Fraser and Duncan, 1998) who concluded that minimizing suffering is the main priority, where enabling animals to engage in normal behaviors and "pleasures" is also considered important but of lower priority than the former. In short, our findings indicate farmers consider both health and natural behaviors to be important for welfare, judging welfare to be "best" when both are supported, but, when there is a trade-off between the two, minimizing health issues takes priority.

When individual characteristics are accounted for, interesting nuances in attitudes toward the importance of health and natural behaviors and their impact on judgements of welfare are notable. This supports previous findings which suggest greater heterogeneity amongst farmers in attitudes to natural behaviors (e.g., Bourlakis et al., 2007; Skarstad et al., 2007; Spooner et al., 2014b). For instance, gender was found to influence attitudes to health and natural behaviors, with female participants found to give higher ratings for the importance of natural behaviors than males. This is line with a large body of research on the effects of gender on attitudes to animal welfare, where females are largely known to be more concerned by animal welfare (Herzog, 2007; Apostol et al., 2013; Clark et al., 2016). However, much of this research focuses on members of the public, with few studies examining the impact of gender on farmers' welfarerelated attitudes. This study is notable for its large proportion of female participants $(47 \%)$, perhaps reflective of a noted increase in female participation in the agriculture workforce in recent years [from $26.3 \%$ in 2005 to $28.4 \%$ in 2016 in the EU, see DaSilva et al. (2018)]. However, the gender configuration of this study is not representative of the agricultural workforce, where (in 2016) $15 \%$ of farmers in the UK and $10.8 \%$ in the Republic of 
Ireland were female (DaSilva et al., 2018). The high proportion of females choosing to participate in this study may thus be a further example of the greater interest females take in animal welfare.

Interestingly, participants who kept their animals outdoors all year round were more likely to give higher ratings for the importance of promoting natural behaviors. This suggests that participants with such a system, where animals arguably have greater opportunity to engage in natural behaviors, place greater emphasis on the importance of natural behaviors within their conceptions of welfare. Such findings support suggestions in the literature that farmers' attitudes to welfare may be influenced by their production system or management practices (Bourlakis et al., 2007; FAWC, 2011; Spooner et al., 2014b) and that differences in production systems are associated with differences in attitudes to welfare (Kjaernes et al., 2007). However, the converse may also be possible, where farmers' may choose management and production systems that are in line with and reflect their values and definitions of animal welfare (Dockès and Kling-Eveillard, 2006; Vigors and Lawrence, 2019). Whatever the direction of this effect, the findings do suggest that the type of production or management system a farmer has, influences the emphasis they place on health and natural behaviors. However, analysis of the effects of gender and management system on attitudes to natural behaviors were not adjusted for multiple testing. Consequently, they may not remain significant at the 5\% level if adjusted for other predictors. The direction of their effect is thus important but should be interpreted with caution.

Type of farm-business also impacted judgements of the vignettes, where having a family-run business was associated with more positive judgements of well-being, physical and mental health, and productivity, and having a commercial partnership was associated with more positive judgements of well-being, physical health, and mental health. Few studies have directly investigated the impact of business type on welfare-related decisions making it difficult to interpret the potential reasons for this finding. However, Macken-Walsh et al. (2012), in an indepth qualitative study into the experiences of Irish beef farmers on family-run farms, explicitly describes the "sense of well-being and satisfaction [they] attained from their interactions with and care of livestock" (p. 10). The care they provided to their animals was a key source of personal enjoyment, intertwined with their self-identity and self-worth. In addition, family-run farms are characterized by farmers and their family as the primary animal care-givers and primary source of labor (Gray, 1998) which may mean they are more likely to know individual animals and have direct and regular interaction with their livestock. As such, the cultural capital family-run farms ascribe to caring for livestock (Macken-Walsh et al., 2012) and the attitudes they may develop from directly working with their animals may have influenced how participants from family-run farms judged welfare in the vignette scenarios. Although there has been research into the economic and social benefits of commercial farm partnerships (e.g., Macken-Walsh and Roche, 2012), this has not examined the impact of such partnerships on the farmers' relationship with or attitudes to their animals' welfare. Consequently, it is difficult to suggest what may underlie the more positive judgements of well-being, physical and mental health given by participants with a commercial partnership, beyond noting its effect.

The type of farming sector also had an impact on participants' judgements. Specifically, participants from the beef sector judged well-being, physical health and productivity more positively. Beef farming in the UK and Ireland is largely characterized by extensive grassland systems (Rath and Peel, 2005; Hennessy et al., 2018). As such, participating beef farmers potentially judged the vignette scenarios from the personal viewpoint of animals with outdoor access, opportunities to form social interactions, exert some agency and express natural behaviors and therefore, may perceive that direct intervention to promote natural behaviors is not necessary (Vigors and Lawrence, 2019). Thus, they may be more likely to judge the well-being, physical health, and productivity of the animals more positively than farmers from other sectors. Nevertheless, sheep producers in the UK and Ireland also have a similar extensive production system, yet a similar effect was not noted for their judgements. However, it is important to note that "beef sector" was one of the largest samples in this study. As such, comparisons between it and other sectors should be interpreted with caution.

Interestingly, participants in the dairy sector judged mental health to be lower than those in other farming sectors. Previous research on UK dairy farmers' attitudes to animals found that $90 \%$ thought cows had feelings and $78 \%$ considered cows to be intelligent (Bertenshaw and Rowlinson, 2009). Notably, Hansson and Lagerkvist (2016) found that, when it came to animal-welfare related decision-making, dairy farmers were more motivated by non-use values (i.e., those relating to animal well-being) than by use-values (i.e., those relating to economic output, such as productivity). Indeed they argued that their findings "suggest that profitability of the business is important but that the absolute rights the animals are assumed to have and the feelings of happiness associated with treating animals well are equally, or even more important" (Hansson and Lagerkvist, 2016, p. 590). Thus, it is possible that dairy farmers may give greater consideration to animal mental health-due to its potential relevance to non-use welfare attributes, the value they place on these and their perception of cows as sentient-resulting in them judging the mental health of the animals in this study more critically than farmers from other sectors. However, without further research it is difficult to determine the nature and source of this association between dairy farmers and judgements of animal mental health.

Finding differences between farming sectors in how they judged or appraised aspects of welfare is important; it highlights how different sub-sets of farmers may have different priorities for welfare influenced by the norms and characteristics of their sector and system. This, arguably, may impact how different sectors respond to policies put forth to address wider societal issues. For example, a recent proposal by the UK National Beef Association to introduce a "carbon tax" for cattle slaughtered later than 27 months of age received criticism from many beef farmers, arguing it would discourage less intensive and regenerative farming practices (e.g., mob grazing) (Riley and Price, 2020). As discussed, the norm 
for beef farmers in the UK is extensive grassland systems and they perceive that opportunities for animals to express natural behaviors are inherent in such a system (Vigors and Lawrence, 2019). When such sector norms and characteristics are considered it is thus possible to understand the negative response of some farmers" to the "carbon-tax" proposal. By revealing potential differences between sectors in how farmers judged different aspects of welfare (and therefore the emphasis they may place on them), the findings of this study are particularly relevant to policy discussions which seek to relate animal welfare to sustainability and climate change. Interestingly, neither membership of assurance scheme nor country (i.e., $\mathrm{UK}, \mathrm{ROI})$ were found to explain any of the variance in participants' vignette judgements or their attitudes to health and natural behaviors. However, a greater proportion of Irish participants were members of assurance schemes. This perhaps reflects differences in assurance scheme structure between the two countries, where the Irish context is largely characterized by a singular, state-run assurance scheme while the UK is characterized by numerous, market-based assurance schemes. As such, differences in policy (i.e., between country) do appear to impact participant characteristics but were not found to effect participants' judgements and attitudes. Nevertheless, future research examining differences in health and natural behavior perspectives between farmers operating under different policy conditions would be helpful, potentially enabling a better understanding of how policy could impact farmers' judgement and decision-making.

BAM was also found to have an impact on judgements of productivity, with participants with a higher BAM judging productivity more positively than those with a lower level of BAM. This is somewhat surprising, as it appears to suggest that participants who believe more strongly in animals as sentient beings believe they are also more capable of being productive under varying conditions of health and natural behavior provision. However, in a study of human-livestock relations in Scotland, Wilkie (2005) reports how commercial livestock production is characterized by livestock viewed as "sentient commodities." That is, farm animals are paradoxically positioned by their caretakers as both units of production and "co-workers" capable of feeling, thought and a life of their own (Wilkie, 2005). As such, it is possible that productivity and belief in animal mind may operate in parallel within farmers' perceptions of their animals, were those who believe more in an animal's mental capacity also give greater credence to their ability to be productive under varying conditions. In addition, there is research to suggest that positive human-animal interactions increase productivity, where positive attitudes to animals (e.g., viewing them as intelligent, capable of feeling) are a reliable predictor of such positive behaviors (Bertenshaw and Rowlinson, 2009). Thus, it may also be possible that the participants, in this study, with a greater belief in animal mind engage in more positive human-animal interactions and experience higher levels of productivity on their own farm. Consequently, they may have judged the vignette scenarios in this study through the lens of their own personal experiences and more positively rated the ability of the animals to be productive. Without additional research, however, it is difficult to satisfactorily account for this finding.

This study demonstrates that farmers do place considerable importance on both minimizing health issues and promoting natural behaviors within animal welfare, where the former is largely given priority over the latter but variances in this exist, often due to individual differences. As such, this study largely supports the view that farmers perceptions of animal welfare are diverse (Kirchner et al., 2014) and vary according to differences in production systems (Bock and van Huik, 2007; Spooner et al., 2012) and attitudes to animals (Hanna et al., 2009). However, the findings of this study are limited by their lack of generalisability to the UK and Irish livestock farmer population and by how health and behavior provision were described in the vignette judgement tasks. The sample size was small and dominated by beef and sheep farmers with extensive systems. Consequently, relating the findings of this study to intensive farming systems and related sectors (e.g., pig and poultry) should be done with caution, particularly as the large representation of extensive systems in the sample may have impacted responses relating to natural behaviors. Moreover, as discussed above, the large proportion of female respondents is not representative of gender in livestock farming, potentially influencing responses as females are known to be more sympathetic toward animal welfare (Clark et al., 2016). The vignettes were created using phrases, sentences, and terms used by livestock farmers when describing health and natural behaviors, collected in a previous qualitative study (see Vigors and Lawrence, 2019).This was done to ensure the vignettes were reflective of real-world situations whilst also being phrased in the language farmers use. However, this also means that the aspects of health and natural behaviors presented to participants do not fully reflect how health and natural behaviors are constructed within the welfare science literature. In addition, it is difficult to account for how individual participants may have interpreted "health" and "natural behaviors." Although a descriptor of what they can be taken to mean was included alongside the vignette narratives, it is possible that, given the diverse nature of the sample (e.g., multiple sectors), participants interpreted these terms differently potentially impacting their responses. Nevertheless, the societal importance of natural behaviors remains; while a public and consumer demand for natural behaviors continues to exist, understanding farmers' point of view, and therefore their ability to respond to public expectations arguably remains important, particularly in the context of wider policy debates on "sustainable intensification," food security, and climate change (e.g., Garnett et al., 2013; Shields and Orme-Evans, 2015).

\section{CONCLUSION}

The findings of this study provide a clearer understanding of the importance farmers give to health and natural behaviors and how different levels of their provision impact farmers' judgements of welfare. In addition, it contributes to research which finds greater heterogeneity in farmers' attitudes to natural behaviors by providing insights on individual characteristics which may account for these differences. Overall, findings indicate that 
farmers value both health and natural behaviors and judge welfare to be at its best when both are supported. However, findings do suggest that priority is given to minimizing health issues and this appears to be central to farmers' welfare-related judgements. Such findings are of particular significance in light of growing scientific and societal interest in supporting positive aspects of welfare and the impact of this for farmers' social license to farm. Although health is a priority issue for farmers, they may increasingly need to demonstrate the importance they give to natural behaviors. Critically, this study also highlights the relevance of individual characteristics when seeking to understand how farmers approach and judge aspects of welfare, particularly natural behaviors. Arguably, a farmer's attitudes toward welfare and their welfare-related decision-making cannot be separated from their personal values, beliefs and experiences. Such insights may become increasingly important for policy debates on climate change and sustainability-farmers' positive or negative response to policies aimed at addressing sustainability and climate change (e.g., increasing efficiency) may be impacted by their welfare priorities-highlighting the growing need for animal welfare to inform and be integrated into these debates.

\section{DATA AVAILABILITY STATEMENT}

The raw data supporting the conclusions of this article will be made available by the authors, without undue reservation.

\section{REFERENCES}

Apostol, L., Rebega, O. L., and Miclea, M. (2013). Psychological and sociodemographic predictors of attitudes toward animals. Procedia Social Behav. Sci. 78, 521-525. doi: 10.1016/j.sbspro.2013.04.343

Appleby, M. C., Weary, D. M., and Sandøe, P. (eds) (2014). Dilemmas in Animal Welfare. CABI. Available online at: http://www.ezproxy.is.ed.ac.uk/login?url= http://www.cabi.org/cabebooks/ebook/20143138804

Atzmüller, C., and Steiner, P. M. (2010). Experimental vignette studies in survey research. Methodology 6, 128-138. doi: 10.1027/1614-2241/ a000014

Bertenshaw, C., and Rowlinson, P. (2009). Exploring stock managers' perceptions of the human-animal relationship on dairy farms and an association with milk production. Anthrozoös 22, 59-69. doi: 10.2752/175303708X3 90473

Bicchieri, C. (2016). Measuring Social Norms. Penn Social Norms Group, University of Pennsylvania, USA. Available online at: http://irh.org/wp-content/uploads/ 2016/09/Bicchieri_MeasuringSocialNorms.pdf

Bock, B. B., and van Huik, M. M. (2007). Animal welfare: the attitudes and behaviour of European pig farmers. Br. Food J. 109, 931-944. doi: 10.1108/00070700710835732

Boissy, A., Manteuffel, G., Jensen, M. B., Moe, R. O., Spruijt, B., Keeling, L. J., et al. (2007). Assessment of positive emotions in animals to improve their welfare. Physiol. Behav. 92, 375-397. doi: 10.1016/j.physbeh.2007.02.003

Bourlakis, M., Hubbard, C., Bourlakis, M., and Garrod, G. (2007). Pig in the middle: farmers and the delivery of farm animal welfare standards. $\mathrm{Br}$. Food J. 109, 919-930. doi: 10.1108/00070700710835723

Buller, H., Blokhuis, H., Jensen, P., and Keeling, L. (2018). Towards farm animal welfare and sustainability. Animals 8:81. doi: 10.3390/ani8060081

Clark, B., Stewart, G. B., Panzone, L. A., Kyriazakis, I., and Frewer, L. J. (2016). A systematic review of public attitudes, perceptions and behaviours towards production diseases associated with farm animal Welfare. J. Agricult. Environ. Ethics 29, 455-478. doi: 10.1007/s10806-016-9615-x

Clay, N., Garnett, T., and Lorimer, J. (2020). Dairy intensification: drivers, impacts and alternatives. Ambio 49, 35-48. doi: 10.1007/s13280-019-01177-y

\section{ETHICS STATEMENT}

The studies involving human participants were reviewed and approved by Social Science Ethics Committee, Scotland's Rural College, Edinburgh, UK. The patients/participants provided their written informed consent to participate in this study.

\section{AUTHOR CONTRIBUTIONS}

BV: conceptualization, methodology, formal analysis, investigation, writing-original draft, and visualization. DE: validation and formal analysis. AL: conceptualization, methodology, writing-review and editing, funding acquisition. All authors contributed to the article and approved the submitted version.

\section{FUNDING}

The authors gratefully acknowledge funding from the Scottish Government's Rural and Environment Science and Analytical Services Division (RESAS) to conduct this research.

\section{SUPPLEMENTARY MATERIAL}

The Supplementary Material for this article can be found online at: https://www.frontiersin.org/articles/10.3389/fanim. 2021.638782/full\#supplementary-material

Cornish, A., Raubenheimer, D., and McGreevy, P. (2016). What we know about the public's level of concern for farm animal Welfare in Food production in developed countries. Animals 6:74. doi: 10.3390/ani6110074

DaSilva, M., Utvik, K., and Colantonio, M. (2018). Agriculture, Forestry and Fishery Statistics: 2018 Edition (Agriculture and Fisheries Collection: Statistical Books, p. 200). Eurostat. Available online at: https://ec.europa.eu/eurostat/ documents/3217494/9455154/KS-FK-18-001-EN-N.pdf/a9ddd7db-c40c48c9-8ed5-a8a90f4faa3f

Dockès, A. C., and Kling-Eveillard, F. (2006). Farmers' and advisers' representations of animals and animal welfare. Livestock Sci. 103, 243-249. doi: 10.1016/j.livsci.2006.05.012

European Commission (2017). Agri-Environmental Indicator: IntensificationExtensification. Available online at: https://ec.europa.eu/eurostat/ statistics- explained/index.php?title=Agri- environmental_indicator_-_intensification_-_extensificationandoldid=350689\#Indicator_definition

European Commission (2020). A Farm to Fork Strategy for a Fair, Healthy and Environmentally-Friendly Food System. (Communication from the Commission to the European Parliament, the Council, the European Economic and Social Committee and the Committee of the Regions, pp. 1-18). European Union. Available online at: https://eur-lex.europa.eu/resource.html?uri=cellar: ea0f9f73-9ab2-11ea-9d2d-01aa75ed71a1.0001.02/DOC_1\&format=PDF

Faucitano, L., Martelli, G., Nannoni, E., and Widowski, T. (2017). "Chapter 21fundamentals of animal welfare in meat animals and consumer attitudes to animal Welfare," in Woodhead Publishing Series in Food Science, Technology and Nutrition, New Aspects of Meat Quality, ed P. P. Purslow. (Woodhead Publishing), 537-568. doi: 10.1016/B978-0-08-100593-4.00021-7

FAWC (2011). Economics and Farm Animal Welfare. Farm Animal Welfare Committee, 1-52. Available online at: https://assets.publishing.service.gov.uk/ government/uploads/system/uploads/attachment_data/file/324964/FAWC_ report_on_economics_and_farm_animal_welfare.pdf

Fraser, D., and Duncan, I. J. H. (1998). "Pleasures", 'Pains' and animal welfare: toward a natural history of affect. Animal Welfare 7, 383-396.

Garnett, T., Appleby, M. C., Balmford, A., Bateman, I. J., Benton, T. G., Bloomer, P., et al. (2013). Sustainable Intensification in agriculture: premises and policies. Science 341, 33-34. doi: 10.1126/science. 1234485 
Gray, J. (1998). Family farms in the Scottish borders: a practical definition by hill sheep farmers. J. Rural Stud. 14, 341-356. doi: 10.1016/S0743-0167(98)00010-2

Hanna, D., Sneddon, I. A., and Beattie, V. E. (2009). The relationship between the stockperson's personality and attitudes and the productivity of dairy cows. Animal 3, 737-743. doi: 10.1017/S1751731109003991

Hansson, H., and Johan Lagerkvist, C. (2012). Measuring farmers' attitudes to animal welfare and health. Br Food J. 114, 840-852. doi: $10.1108 / 00070701211234363$

Hansson, H., and Lagerkvist, C. J. (2016). Dairy farmers' use and non-use values in animal welfare: determining the empirical content and structure with anchored best-worst scaling. J. Dairy Sci. 99, 579-592. doi: 10.3168/jds.2015-9755

Hansson, H., Lagerkvist, C. J., and Vesala, K. M. (2018). Impact of personal values and personality on motivational factors for farmers to work with farm animal welfare: a case of Swedish dairy farmers. Animal Welfare 27, 133-145. doi: $10.7120 / 09627286.27 .2 .133$

Hennessy, T., Doran, J., Bogue, J., and Repar, L. (2018). The Economic and Societal Importance of the Irish Suckler Beef Sector. Irish Farmers Association, 83.

Henson, S., and Reardon, T. (2005). Private agri-food standards: Implications for food policy and the agri-food system. Food Policy 30, 241-253. doi: 10.1016/j.foodpol.2005.05.002

Herzog, H. A. (2007). Gender differences in human-animal interactions: a review. Anthrozoös 20, 7-21. doi: 10.2752/089279307780216687

Hills, A. M. (1995). Empathy and belief in the mental experience of animals. Anthrozoös 8, 132-142. doi: 10.2752/089279395787156347

Hox, J. J., Kreft, I. G. G., and Hermkens, P. L. J. (1991). Analysing factorial surveys. Sociol. Methods Res. 19, 493-510. doi: 10.1177/0049124191019004003

IBM Corp. (2017). IBM SPSS Statistics for Windows. Armonk, NY: IBM Corp.

Kauppinen, T., Vainio, A., Valros, A., Rita, H., and Vesala, K. M. (2010). Improving animal welfare: qualitative and quantitative methodology in the study of farmers' attitudes. Animal Welfare 19:523.

Kielland, C., Skjerve, E., Østerås, O., and Zanella, A. J. (2010). Dairy farmer attitudes and empathy toward animals are associated with animal welfare indicators. J. Dairy Sci. 93, 2998-3006. doi: 10.3168/jds.2009-2899

Kirchner, M. K., Westerath-Niklaus, H. S., Knierim, U., Tessitore, E., Cozzi, G., Vogl, C., et al. (2014). Attitudes and expectations of beef farmers in Austria, Germany and Italy towards the Welfare Quality $\AA$ assessment system. Livestock Sci. 160, 102-112. doi: 10.1016/j.livsci.2013.12.004

Kjaernes, U., Bock, B., Roe, E., and Roex, J. (2008). Consumption, Distribution and Production of Farm Animal Welfare: Opinions and Practices Within the Supply Chain. Cardiff University, School of City and Regional Planning.

Kjaernes, U., Miele, M., and Roex, J. (2007). Attitudes of Consumers, Retailers and Producers to Farm Animal Welfare. Welfare Quality Reports No. 2. Welfare Quality: Science and Society Improving Animal Welfare. Cardiff: European Commission.

Knight, S., Vrij, A., Cherryman, J., and Nunkoosing, K. (2004). Attitudes towards animal use and belief in animal mind. Anthrozoös 17, 43-62. doi: $10.2752 / 089279304786991945$

Kristensen, E., and Jakobsen, E. B. (2011). Challenging the myth of the irrational dairy farmer; understanding decision-making related to herd health. $N$. Zealand Vet. J. 59, 1-7. doi: 10.1080/00480169.2011.547162

Lawrence, A. B., Vigors, B., and Sandøe, P. (2019). What is so positive about positive animal welfare?-A critical review of the literature. Animals 9:783. doi: 10.3390/ani9100783

Lundmark, F., Berg, C., and Röcklinsberg, H. (2018). Private animal welfare standards-opportunities and risks. Animals 8:4. doi: 10.3390/ani8010004

Macken-Walsh, Á., Crosson, P., and Murray, A. (2012). A Qualitative Study of Irish Beef Farmers' Production Decisions: Summary and Implications for Extension. Rural Economy and Development Programme (Teagasc), 20.

Macken-Walsh, Á., and Roche, B. (2012). Facilitating Farmers' Establishment of Farm Partnerships: A Participatory Template. Teagasc.

Mellor, D. (2012). Animal emotions, behaviour and the promotion of positive welfare states. N. Zealand Vet. J. 60, 1-8. doi: 10.1080/00480169.2011.619047

Miele, M. (2010). Report Concerning Consumer Perceptions and Attitudes Towards Farm Animal Welfare. European Animal Welfare Platform, 1-16.

Miele, M., Veissier, I., Evans, A., and Botreau, R. (2011). Animal welfare: establishing a dialogue between science and society. Animal Welfare 20, 103.

Rath, M., and Peel, S. (2005). "Grassland in Ireland and the UK," in Grassland: A Global Resource, eds D. A. McGilloway (Wageningen: Wageningen Academic Publishers), 13-27.
Rayner, A. C., Newberry, R. C., Vas, J., and Mullan, S. (2020). Slow-growing broilers are healthier and express more behavioural indicators of positive welfare. Sci. Rep. 10:15151. doi: 10.1038/s41598-020-72198-x

Riley, J., and Price, R. (2020). Beef Farmers Split Over 'carbon tax' Plan for Older Cattle. Farmers Weekly. Available online at: https://www.fwi.co.uk/livestock/ beef/beef-farmers-split-over-carbon-tax-plan-for-older-cattle

Sandøe, P., Corr, S., Lund, T., and Forkman, B. (2019). Aggregating animal welfare indicators: can it be done in a transparent and ethically robust way? Animal Welfare 28, 67-76. doi: 10.7120/09627286.28.1.067

Shields, S., and Orme-Evans, G. (2015). The impacts of climate change mitigation strategies on animal Welfare. Animals 5, 361-394. doi: 10.3390/ani5020361

Skarstad, G. A., Terragni, L., and Torjusen, H. (2007). Animal welfare according to Norwegian consumers and producers: definitions and implications. Int. J. Sociol. Food Agriculture 15, 74-90. Available online at: https://www.semanticscholar.org/paper/Animalwelfare-according-to-Norwegian-consumers-and-Skarstad-Terragni/ da41bb62d8213e9385223ef7aa690373e1e16a27

Spooner, J., Schuppli, C., and Fraser, D. (2012). Attitudes of Canadian beef producers toward animal welfare. Animal Welfare 21, 273-283. doi: 10.7120/09627286.21.2.273

Spooner, J. M., Schuppli, C. A., and Fraser, D. (2014a). Attitudes of Canadian citizens toward farm animal welfare: a qualitative study. Livestock Sci. 163, 150-158. doi: 10.1016/j.livsci.2014.02.011

Spooner, J. M., Schuppli, C. A., and Fraser, D. (2014b). Attitudes of canadian pig producers toward animal Welfare. J. Agricult. Environ. Ethics 27, 569-589. doi: 10.1007/s10806-013-9477-4

Taylor, B. J. (2006). Factorial surveys: using vignettes to study professional judgement. Br. J. Social Work 36, 1187-1207. doi: 10.1093/bjsw/ bch345

Te Velde, H., Aarts, N., and Van Woerkum, C. (2002). Dealing with ambivalence: farmers' and consumers' perceptions of animal welfare in livestock breeding. J. Agricult. Environ. Ethics 15, 203-219. doi: 10.1023/A:1015012403331

Thorslund, C. A. H., Sandøe, P., Aaslyng, M. D., and Lassen, J. (2016). A good taste in the meat, a good taste in the mouth - Animal welfare as an aspect of pork quality in three European countries. Livestock Sci. 193, 58-65. doi: 10.1016/j.livsci.2016.09.007

Vanhonacker, F., Verbeke, W., Van Poucke, E., and Tuyttens, F. A. M. (2008). Do citizens and farmers interpret the concept of farm animal welfare differently? Livestock Sci. 116, 126-136. doi: 10.1016/j.livsci.2007.09.017

Vigors, B. (2019). Citizens' and Farmers' Framing of 'Positive Animal Welfare' and the implications for framing positive welfare in communication. Animals 9:147. doi: 10.3390/ani9040147

Vigors, B., and Lawrence, A. (2019). What are the positives? exploring positive welfare indicators in a qualitative interview study with livestock farmers. Animals 9:694. doi: 10.3390/ani9090694

Vogeler, C. S. (2019). Market-based governance in farm animal welfare-a comparative analysis of public and private policies in Germany and France. Animals 9:267. doi: 10.3390/ani9050267

Weary, D., and Robbins, J. (2019). Understanding the multiple conceptions of animal welfare. Anim. Welfare 28, 33-40. doi: 10.7120/09627286.28.1.033

Wilkie, R. (2005). Sentient commodities and productive paradoxes: The ambiguous nature of human-livestock relations in Northeast Scotland. J. Rural Stud. 21, 213-230. doi: 10.1016/j.jrurstud.2004.10.002

Williams, J., and Martin, P. (2012). Defending the Social Licence of Farming: Issues, Challenges and New Directions for Agriculture. CSIRO Publishing. Available online at: http://ebookcentral.proquest.com/lib/ed/detail.action? docID $=799176$

Conflict of Interest: The authors declare that the research was conducted in the absence of any commercial or financial relationships that could be construed as a potential conflict of interest.

Copyright (c) 2021 Vigors, Ewing and Lawrence. This is an open-access article distributed under the terms of the Creative Commons Attribution License (CC BY). The use, distribution or reproduction in other forums is permitted, provided the original author(s) and the copyright owner(s) are credited and that the original publication in this journal is cited, in accordance with accepted academic practice. No use, distribution or reproduction is permitted which does not comply with these terms. 